Article

\title{
An Experimental Study of the Decomposition and Carbonation of Magnesium Carbonate for Medium Temperature Thermochemical Energy Storage
}

\author{
Daniel Mahon *, Gianfranco Claudio and Philip Eames
}

check for updates

Citation: Mahon, D.; Claudio, G.; Eames, P. An Experimental Study of the Decomposition and Carbonation of Magnesium Carbonate for Medium Temperature Thermochemical Energy Storage. Energies 2021, 14, 1316. https://doi.org/10.3390/en14051316

Academic Editor: Carlos Ortíz

Received: 11 January 2021

Accepted: 22 February 2021

Published: 28 February 2021

Publisher's Note: MDPI stays neutral with regard to jurisdictional claims in published maps and institutional affiliations.

Copyright: (c) 2021 by the authors. Licensee MDPI, Basel, Switzerland. This article is an open access article distributed under the terms and conditions of the Creative Commons Attribution (CC BY) license (https:// creativecommons.org/licenses/by/ $4.0 /)$.
Centre for Renewable Energy Systems Technology (CREST), Wolfson School of Mechanical, Electrical and Manufacturing Engineering, Loughborough University, Loughborough LE11 3TU, UK; g.claudio@lboro.ac.uk (G.C.); p.c.eames@lboro.ac.uk (P.E.)

* Correspondence: d.mahon@lboro.ac.uk

\begin{abstract}
To improve the energy efficiency of an industrial process thermochemical energy storage (TCES) can be used to store excess or typically wasted thermal energy for utilisation later. Magnesium carbonate $\left(\mathrm{MgCO}_{3}\right)$ has a turning temperature of $396{ }^{\circ} \mathrm{C}$, a theoretical potential to store $1387 \mathrm{~J} / \mathrm{g}$ and is low cost ( GBP 400/1000 kg). Research studies that assess $\mathrm{MgCO}_{3}$ for use as a medium temperature TCES material are lacking, and, given its theoretical potential, research to address this is required. Decomposition (charging) tests and carbonation (discharging) tests at a range of different temperatures and pressures, with selected different gases used during the decomposition tests, were conducted to gain a better understanding of the real potential of $\mathrm{MgCO}_{3}$ for medium temperature TCES. The thermal decomposition (charging) of $\mathrm{MgCO}_{3}$ has been investigated using thermal analysis techniques including simultaneous thermogravimetric analysis and differential scanning calorimetry (TGA/DSC), TGA with attached residual gas analyser (RGA) and diffuse reflectance infrared Fourier transform spectroscopy (DRIFTS) (up to $650{ }^{\circ} \mathrm{C}$ ). TGA, DSC and RGA data have been used to quantify the thermal decomposition enthalpy from each $\mathrm{MgCO}_{3} \cdot \mathrm{xH}_{2} \mathrm{O}$ thermal decomposition step and separate the enthalpy from $\mathrm{CO}_{2}$ decomposition and $\mathrm{H}_{2} \mathrm{O}$ decomposition. Thermal analysis experiments were conducted at different temperatures and pressures (up to 40 bar) in a $\mathrm{CO}_{2}$ atmosphere to investigate the carbonation (discharging) and reversibility of the decarbonation-carbonation reactions for $\mathrm{MgCO}_{3}$. Experimental results have shown that $\mathrm{MgCO}_{3} \cdot \mathrm{xH}_{2} \mathrm{O}$ has a three-step thermal decomposition, with a total decomposition enthalpy of $\sim 1050 \mathrm{~J} / \mathrm{g}$ under a nitrogen atmosphere. After normalisation the decomposition enthalpy due to $\mathrm{CO}_{2}$ loss equates to $1030-1054 \mathrm{~J} / \mathrm{g}$. A CO 2 atmosphere is shown to change the thermal decomposition (charging) of $\mathrm{MgCO}_{3} \cdot \mathrm{xH}_{2} \mathrm{O}$, requiring a higher final temperature of $\sim 630{ }^{\circ} \mathrm{C}$ to complete the decarbonation. The charging input power of $\mathrm{MgCO}_{3} \cdot \mathrm{xH}_{2} \mathrm{O}$ was shown to vary from 4 to $8136 \mathrm{~W} / \mathrm{kg}$ with different isothermal temperatures. The carbonation (discharging) of $\mathrm{MgO}$ was found to be problematic at pressures up to 40 bar in a pure $\mathrm{CO}_{2}$ atmosphere. The experimental results presented show $\mathrm{MgCO}_{3}$ has some characteristics that make it a candidate for thermochemical energy storage (high energy storage potential) and other characteristics that are problematic for its use (slow discharge) under the experimental test conditions. This study provides a comprehensive foundation for future research assessing the feasibility of using $\mathrm{MgCO}_{3}$ as a medium temperature TCES material. Future research to determine conditions that improve the carbonation (discharging) process of $\mathrm{MgO}$ is required.
\end{abstract}

Keywords: thermochemical energy storage; magnesium carbonate; thermal energy storage; industrial waste heat; thermal analysis

\section{Introduction}

Over the last decade (2007-2017) the world's primary energy consumption has grown on average by $1.5 \%$ per annum, in 2018 by $2.9 \%$ [1], and the average rate of $\mathrm{CO}_{2}$ emissions has increased on average by $2.1 \%$ each year since 1966 [2]. Figure 1 shows the world's 
$\mathrm{CO}_{2}$ emissions and total energy consumption per year since 1965. Figure 2 shows that the amount of $\mathrm{CO}_{2}$ emissions per unit energy consumption has been decreasing year on year since 1965, suggesting that since 1965 energy production became "cleaner" with time.

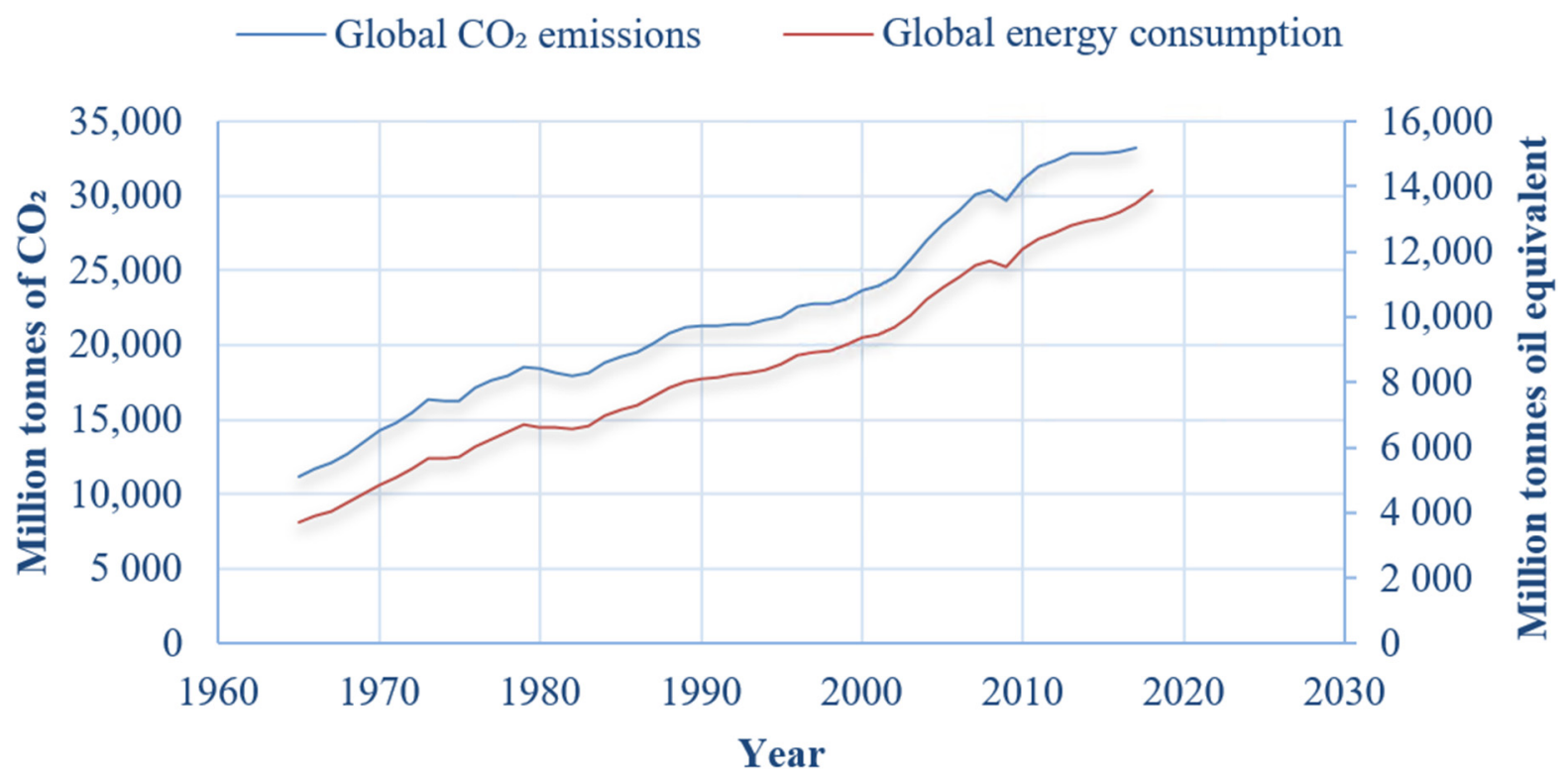

Figure 1. Global man-made $\mathrm{CO}_{2}$ emissions and total energy consumption per annum (plot generated using data from $B P$ Statistical Review of World Energy 2019 [2]).

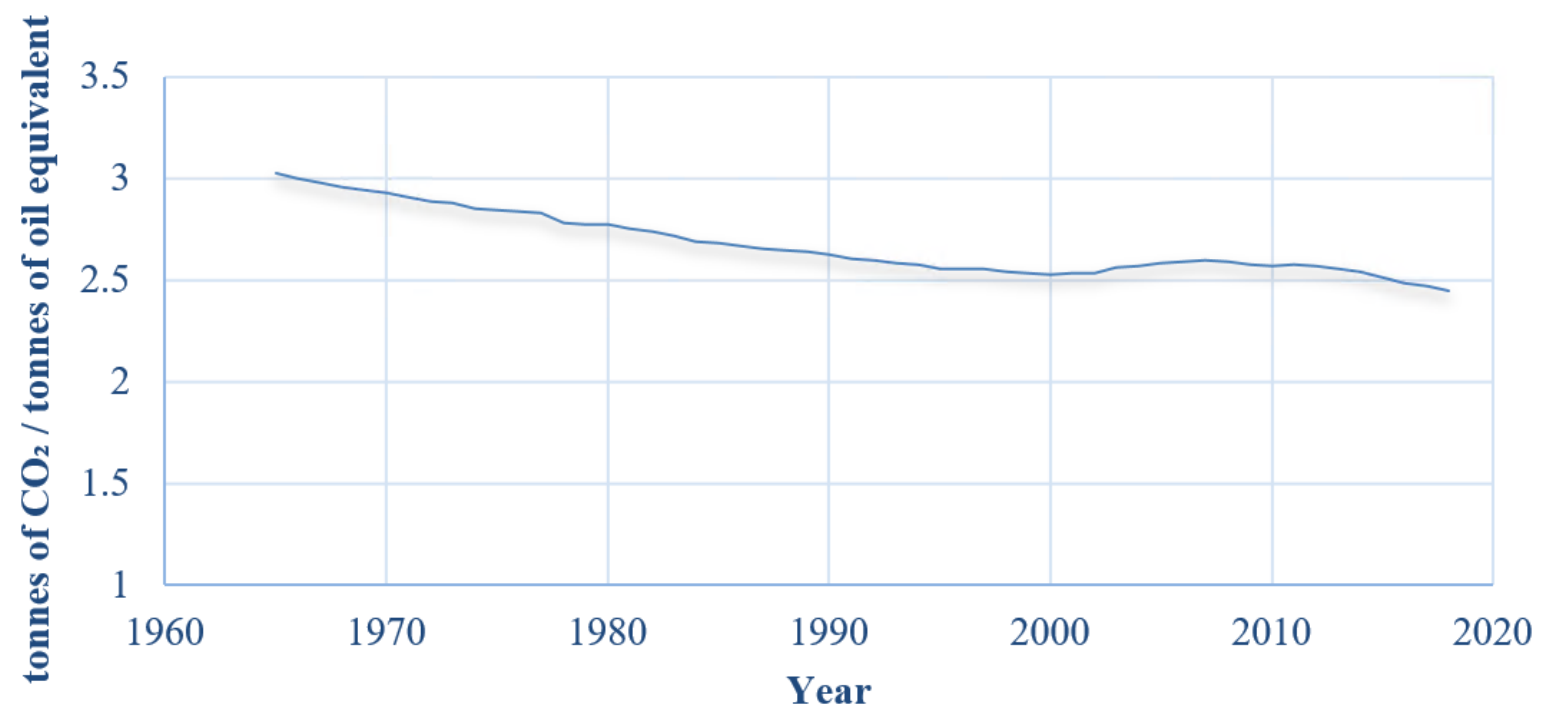

Figure 2. Global average tonnes of $\mathrm{CO}_{2}$ emissions per tonnes of oil equivalent (plot generated using data from BP Statistical Review of World Energy 2019 [2]).

According to a report published by the International Panel on Climate Changes (IPCC), to limit global warming to $1.5^{\circ} \mathrm{C}$ the global $\mathrm{CO}_{2}$ emissions should reach net zero by around 2050 [3]. As the rate of $\mathrm{CO}_{2}$ emissions has been increasing year on year since 1965 at a global scale, if global warming is going to be limited to $1.5^{\circ} \mathrm{C}$ then clearly a dramatic reduction in global $\mathrm{CO}_{2}$ emissions is required. For 2017 and 2018 the percentage of mankind's global primary energy generated from fossil fuels (oil, natural gas and coal) was $85.1 \%$ and $84.7 \%$, respectively [2]. The percentage of mankind's primary energy generated from renewables globally in 2017 and 2018 was $3.6 \%$ and $4.0 \%$, respectively [2]. For the UK the energy mix is slightly different, with $80.1 \%$ and $79.3 \%$ of primary energy generated from fossil 
fuels in 2017 and 2018 and with 10.9\% and 12.4\% of primary energy from renewables, respectively [2]. The UK is above the global average for percentage of mankind's energy generated from renewables; it is however still a long way from being $100 \%$ renewable. The planet as a whole is even further from becoming $100 \%$ renewable with only $4 \%$ of mankind's energy coming from renewables in 2018 [2].

To achieve net zero greenhouse gas emissions industrial processes will also need to be carbon-free and therefore the current waste heat sources available from industrial processes may change from those available today. In the future there will still be waste heat sources generated from carbon-free industrial processes, which could be utilised to improve cost effectiveness and efficiency. This means that while thermal energy storage (TES) may be helpful in the immediate future where fossil fuels are extensively used to generate heat, TES may also be useful in a net zero world. If mankind's energy consumption continues to grow, creative ways to generate clean energy efficiently will be required to meet humanity's energy needs.

In 2019 the UK became the first major economy to pass a net zero emissions law, which legally binds the UK to cut net emissions to zero by 2050 [4].

One possible way to produce more energy without producing additional $\mathrm{CO}_{2}$ is to store waste heat from industrial processes using a TES material and utilise it to meet subsequent heat demands. The final energy consumption of the industry sector in the EU-28 in 2018 was $25.3 \%$ [5]. In the UK there is currently a more than $12 \mathrm{PJ}$ of waste heat available from industrial processes in the temperature range of $700-900{ }^{\circ} \mathrm{C}$ and more than $15 \mathrm{PJ}$ in the range of $500-900{ }^{\circ} \mathrm{C}$, according to a study published in 2014 [6]. Industrial waste heat in this temperature range could be utilised to charge a thermochemical energy storage (TCES) material such as $\mathrm{MgCO}_{3}$. The total final energy consumption in the UK in 2017 was 5911 PJ [7], hence, the available waste heat in this temperature range equates to $0.25 \%$ of the UK's total final energy consumption. In the EU-28 final energy consumption in 2015 was 1090 Mtoe [5] ( 12,700 TWh or 45,600 PJ), with an estimated $124 \mathrm{TWh}$ /year (446 PJ) of waste heat above $500{ }^{\circ} \mathrm{C}$ [8], meaning approximately $1 \%$ of the EU-28 total final energy consumption is converted to waste heat above $500^{\circ} \mathrm{C}$.

The temperature of the waste heat supply, the available space, required energy storage duration and other variables make different TES technologies suited to different applications. For example, if an application required short-duration TES (1-2 days) in the temperature range of $40-70{ }^{\circ} \mathrm{C}$ and a relatively large power output, it is probable that a latent thermal energy storage (LTES) material would be more suited to the application.

TCES allows thermal energy to be stored as chemical potential energy for later use. A key benefit of TCES is the quantity of energy that can be stored per unit mass (the specific energy density). Typically, TCES materials have energy densities significantly larger than LTES and sensible thermal energy storage (STES) materials. TCES materials can be 20 times more energy dense than LTES materials and 34 times more energy dense than STES materials $[9,10]$. As an example, if a $500{ }^{\circ} \mathrm{C}$ heat source is available, using rock as a STES material, with a heat capacity of $0.82 \mathrm{~kJ} / \mathrm{kg} . \mathrm{K}$, to store thermal energy for a discharge at ambient temperature $\left(25^{\circ} \mathrm{C}\right), 390 \mathrm{~J} / \mathrm{g}$ of heat can be stored [11]. If a $\mathrm{Ca}(\mathrm{OH})_{2} \Leftrightarrow \mathrm{CaO}$ $+\mathrm{H}_{2} \mathrm{O}$ TCES system is used, $109 \mathrm{~kJ} / \mathrm{mol}$ [12] or around $1470 \mathrm{~J} / \mathrm{g}$ of heat can potentially be stored in this chemical reaction. Another key benefit of TCES is the chemical potential energy can be stored indefinitely if the chemicals do not react with each other.

There are some losses from TCES systems that are mainly due to the sensible energy lost from the materials during storage. Typically, a TCES material is heated to a specified temperature to separate the component chemicals and then allowed to cool in a charged state until discharge is required. As the TCES material cools thermal energy is lost from the system due to sensible heat losses; however, depending on the thermodynamics of the system, these losses can be low (i.e., $10-15 \%$ of the overall thermal energy stored) and once the sensible heat is lost, in theory, all of the chemical potential energy can be stored indefinitely $[13,14]$. The lower the delta $\mathrm{T}\left({ }^{\circ} \mathrm{C}\right)$ between the charging temperature and the storage temperature, the lower the sensible heat losses will be. 
TCES systems can in theory be developed for a large number of TES applications ranging from relatively low temperatures charging/discharging, at $150{ }^{\circ} \mathrm{C}$ or lower [15], to high temperatures, for example, $\mathrm{CaCO}_{3} \Leftrightarrow \mathrm{CaO}+\mathrm{CO}_{2}$, which has a turning temperature of $837^{\circ} \mathrm{C}$ [12]. The materials used can be single compounds or composites designed to provide improved performance in terms of energy storage and charge/discharge rates.

For example, $\mathrm{MgSO}_{4} \cdot \mathrm{xH}_{2} \mathrm{O}$ has been shown to be a potential domestic TCES material [15], which has the potential to store $1118 \mathrm{~J} / \mathrm{g}\left(496 \mathrm{kWh} / \mathrm{m}^{3}\right.$, assuming a packing density of $60 \%$ ) and a theoretical cost of GBP $64 / 1000 \mathrm{~kg}$ (for $\mathrm{MgSO}_{4}$ ), which equates to a cost of $16.8 \mathrm{p} / \mathrm{kWh}$. If the material could be effectively cycled 30 times, this equates to a cost of $0.6 \mathrm{p} / \mathrm{kWh} . \mathrm{MgCO}_{3}$ has a theoretical specific energy density of $1387 \mathrm{~J} / \mathrm{g}(385 \mathrm{Wh} / \mathrm{kg})$, resulting in a cost of GBP $1.73 / \mathrm{kWh}$ (assuming a packing density of $60 \%$ ) for comparison Li-ion battery technologies have a specific energy density of 75-200 Wh/ kg with a cost of USD 600-2500/kWh [16]. The technology readiness level (TRL) of TCES, however, is much lower than the more developed STES and LTES technologies.

Magnesium carbonate $\left(\mathrm{MgCO}_{3}\right)$ could be used as a potential TCES material for medium temperature applications $\left(400-600^{\circ} \mathrm{C}\right)$ as it has a turning temperature of $397^{\circ} \mathrm{C}[12,17,18]$, making it suitable for storing energy in this temperature range. Minimal experimental studies have been conducted into the charging (decomposition) and the discharging (carbonation) of $\mathrm{MgCO}_{3}$ for use as a medium temperature TCES material. Experimental studies into the charging power, energy density, discharge power of $\mathrm{MgCO}_{3}$ are required at a range of temperatures and pressures to understand the true potential of this material.

A study published in 2019 by Shkatulov et al. investigated the potential of adapting the $\mathrm{MgO}+\mathrm{CO}_{2}$ working pair for TCES for medium temperatures [19]. The study did not look at the thermal decomposition and carbonation of $\mathrm{MgCO}_{3} \cdot \mathrm{xH}_{2} \mathrm{O}$ and only presented results for the salt promoted $\mathrm{MgO}+\mathrm{CO}_{2}$ working pair [19]. This study pointed out some of the promising characteristics of the $\mathrm{MgO}+\mathrm{CO}_{2}$ reaction for TCES, including high value reaction enthalpy, absence of deliquescence and swelling/shrinking on a macroscopic level and noncorrosiveness. This study suggests that one reason why there has not been an assessment of $\mathrm{MgO}+\mathrm{CO}_{2}$ for TCES is due to the difficulty of the carbonation (heat-releasing stage) of the reaction [19] and referenced a study published in 2004 by L'vov et al. [20]. The publication by L'vov et al. [20] used thermogravimetric analysis (TGA) experiments of $\mathrm{MgCO}_{3}, \mathrm{SrCO}_{3}$ and $\mathrm{BaCO}_{3}$ along with data from literature to determine the E parameters of the Arrhenius equation using the third-law method [20]. Within the study's conclusion it suggests that the widely accepted understanding that carbonate decomposition reactions are reversible should be refused [20]. Taking values from the NIST-JANAF thermochemical tables [21], the Gibbs free energy value at standard temperature $(298 \mathrm{~K})$ and pressure for the reaction $\mathrm{MgO}(\mathrm{s})+\mathrm{CO}_{2}(\mathrm{~g})=\mathrm{MgCO}_{3}(\mathrm{~s})$ is calculated as being spontaneous $\left(\Delta \mathrm{G}_{\mathrm{f}}{ }^{\circ}=-0.175 \mathrm{~kJ} / \mathrm{mol}\right)$. The reversibility of the $\mathrm{MgCO}_{3}$ reaction and the carbonation of $\mathrm{Mg}(\mathrm{OH})_{2}$ are discussed in more detail in Sections 3.5 and 3.7.

The focus of this paper is assessing the charging and discharging of $\mathrm{MgCO}_{3}$, a material that theoretically is suitable for TCES in the medium temperature range $\left(400-600{ }^{\circ} \mathrm{C}\right)$, which is used in a range of industrial processes including the iron and steel industry $[6,8]$.

The research presented in this paper reports on an experimental investigation into the potential of $\mathrm{MgCO}_{3}$ for medium temperature TCES. The experimental characterisation aims to determine and understand the decomposition of $\mathrm{MgCO}_{3} \cdot \mathrm{xH}_{2} \mathrm{O}$ when exposed to different gases and to quantify the mass loss, decomposition enthalpy, charging power input and the materials involved in each decomposition step. The discharging of $\mathrm{MgCO}_{3} \cdot \mathrm{xH}_{2} \mathrm{O}$ has also been characterised to understand the discharge power and conversion $(\mathrm{MgO}$ to $\left.\mathrm{MgCO}_{3}\right)$ at different pressures and temperatures.

$\mathrm{MgCO}_{3}$ is theoretically suitable for industrial applications requiring thermal storage in the temperature range of $400-600{ }^{\circ} \mathrm{C}$, due to its turning temperature of $397^{\circ} \mathrm{C}$; our research clearly shows due to very slow kinetics in the discharge reaction under the conditions tested $\mathrm{MgCO}_{3}$ is not a suitable TCES material. The paper describes the temperatures that 
are required to charge $\mathrm{MgCO}_{3}$ under both $\mathrm{N}_{2}$ and $\mathrm{CO}_{2}$ atmospheres and quantifies the enthalpy involved with this charging process. This paper does not define a specific industrial application, for a TCES system using $\mathrm{MgCO}_{3}$ that is theoretically suitable for charging and discharging around the turning temperature of $\mathrm{MgCO}_{3}$. The aim of the research is to understand how and if $\mathrm{MgCO}_{3}$ can store energy, at what temperature in different atmospheres by experimental testing within a range of different conditions. Without these tests we would not know if $\mathrm{MgCO}_{3}$ might be suitable in a specific application requiring TCES within the range of conditions tested or not. The research presented clearly identifies the issues of using $\mathrm{MgCO}_{3}$ for TCES applications. This study also presents a methodology that uses TGA, residual gas analysis (RGA) and differential scanning calorimetry (DSC) data for characterising the mass loss and enthalpy for the specific components of the $\mathrm{MgCO}_{3} \cdot \mathrm{xH}_{2} \mathrm{O}$ thermal decomposition. Experimental data of the decomposition of $\mathrm{MgCO}_{3} \cdot \mathrm{xH}_{2} \mathrm{O}$ at selected isothermal temperatures have been presented and show that at around $500{ }^{\circ} \mathrm{C}$ the decomposition kinetics decrease before increasing again at higher temperatures. This is a result not previously presented in the literature, and understanding if the decomposition kinetics can be improved, around $500{ }^{\circ} \mathrm{C}$, requires future investigation as this impacts the charging input power achieved for $\mathrm{MgCO}_{3} \cdot \mathrm{xH}_{2} \mathrm{O}$.

This paper shows that $\mathrm{MgCO}_{3}$ has the ability to store $1054 \mathrm{~J} / \mathrm{g}\left(520 \mathrm{kWh} / \mathrm{m}^{3}\right.$, assuming a $60 \%$ packing density); the discharge phase (carbonation of $\mathrm{MgO}$ ) of this proposed TCES system, however, is shown to be problematic at pressures up to 40 bar and temperatures up to $300^{\circ} \mathrm{C}$. This research shows the potential of $\mathrm{MgCO}_{3}$ for medium temperature TCES; however, if $\mathrm{MgCO}_{3}$ is to be used in a TCES system more research is required into the discharge reaction to determine if it is possible to extract the stored thermal energy with sufficient power, doing this may require the development of composite materials containing $\mathrm{MgCO}_{3}$ or the testing of $\mathrm{MgCO}_{3}$ under different conditions.

\section{Materials and Methods}

To test the decomposition of $\mathrm{MgCO}_{3} \cdot \mathrm{xH}_{2} \mathrm{O}$ a Mettler Toledo TGA/DSC 3+ simultaneous TGA and DSC with a $\mathrm{N}_{2}$ purge gas at $50 \mathrm{~mL} / \mathrm{min}$ was used. This device was used to measure the decomposition heat flow data as well as the decomposition mass loss with time and temperature. The sample size used in this device varied between 7-15 mg contained within a $70 \mu \mathrm{l}$ alumina sample pan without any lid, unless otherwise stated.

The mass loss during decomposition of the samples and the volatile gas being released from the samples with increasing temperature was measured using a TA Instruments Discovery TGA with attached MKS Cirrus 2 Residual Gas Analyser (RGA). The samples were purged with $\mathrm{N}_{2}$ at a flow rate of $50 \mathrm{~mL} / \mathrm{min}$, and the sample size used was typically $<4 \mathrm{mg}$. The sample pans used for the TGA + RGA tests were $100 \mu$ platinum pans.

TGA, RGA and DSC data were used to quantify the decomposition heat flow and mass loss occurring due to both $\mathrm{CO}_{2}$ and $\mathrm{H}_{2} \mathrm{O}$ evolution from a $\mathrm{MgCO}_{3} \cdot \mathrm{xH}_{2} \mathrm{O}$ sample where both $\mathrm{CO}_{2}$ and $\mathrm{H}_{2} \mathrm{O}$ are being decomposed from the sample simultaneously. The methodology for conducting this analysis is explained in more detail in Section 3.1.

To assess the change in mass with pressure of the treated $\mathrm{MgCO}_{3} \cdot \mathrm{xH}_{2} \mathrm{O}$ sample $(\mathrm{MgO})$ a HIDEN Isochema XEMIS high-pressure thermogravimetric analyser was used. This device can run experiments at pressures from vacuum up to 170 bar and temperatures up to $500{ }^{\circ} \mathrm{C}$. Connected to this system was premium grade $\mathrm{CO}_{2}$ and technical grade $\mathrm{N}_{2}$. The device can perform fixed volume and fixed pressure experiments. While running in fixed pressure mode (i.e., with a purge gas) the sample can be exposed to a specified mixture of the connected gases, for example, if required, a sample could be exposed to 10 bar of $20 \% \mathrm{CO}_{2}$ and $80 \% \mathrm{~N}_{2}$ gas at a flow rate of $100 \mathrm{~mL} / \mathrm{min}$. In situ decomposition and high-pressure carbonation experiments were conducted using this device. The samples were tested in stainless steel mesh hanging pans, which allowed gases to easily access the sample.

Fourier transform infrared spectroscopy (FT-IR) was used to measure the absorbance of light at different wavelengths by the samples. The device used was a ThermoFisher 
Nicolet iS-50. The iS-50 was equipped with a Harrick Scientific Praying Mantis with a high-temperature and high-pressure reaction dome. Diffuse reflectance infrared Fourier transform spectroscopy (DRIFTS) experiments were conducted using this setup. The changing absorbance spectrum was recorded with time to evaluate how the samples changed as they were heated and thermally decomposed at varying temperature. Each of the DRIFTS samples was made with a mixture of $\mathrm{KBr}$ and the sample in a ratio of $95 \mathrm{wt} \%$ to $5 \mathrm{wt} \%$, respectively. The samples were ground and mixed in a mortar and pestle before being loaded into the FT-IR.

\section{Results and Discussion}

Initial thermal decomposition characterisation experiments of $\mathrm{MgCO}_{3} \cdot \mathrm{xH}_{2} \mathrm{O}$ were conducted using the combined TGA/DSC. Figure 3 shows the TGA mass loss data, DSC heat flow data and dTGA differential mass loss data from a TGA/DSC test of $\mathrm{MgCO}_{3} \cdot \mathrm{xH}_{2} \mathrm{O}$. The device used for these tests shown on Figure 3 was a Mettler Toledo TGA/DSC $3+$ and the sample size ranged from $7-15 \mathrm{mg}$, the heating rate was $5{ }^{\circ} \mathrm{C} / \mathrm{min}$. The decomposition evolved in a three-step process. The first step was small and not annotated on Figure 3. The second step peaked at $245{ }^{\circ} \mathrm{C}$ and resulted in an average mass loss of $14 \%$ and an average enthalpy of $261 \mathrm{~J} / \mathrm{g}$. The third step was the largest step, which peaked at $441{ }^{\circ} \mathrm{C}$ with an average mass loss of $40 \%$ and an average enthalpy of $778 \mathrm{~J} / \mathrm{g}$. The average results were calculated using the results of several TGA/DSC and TGA tests.

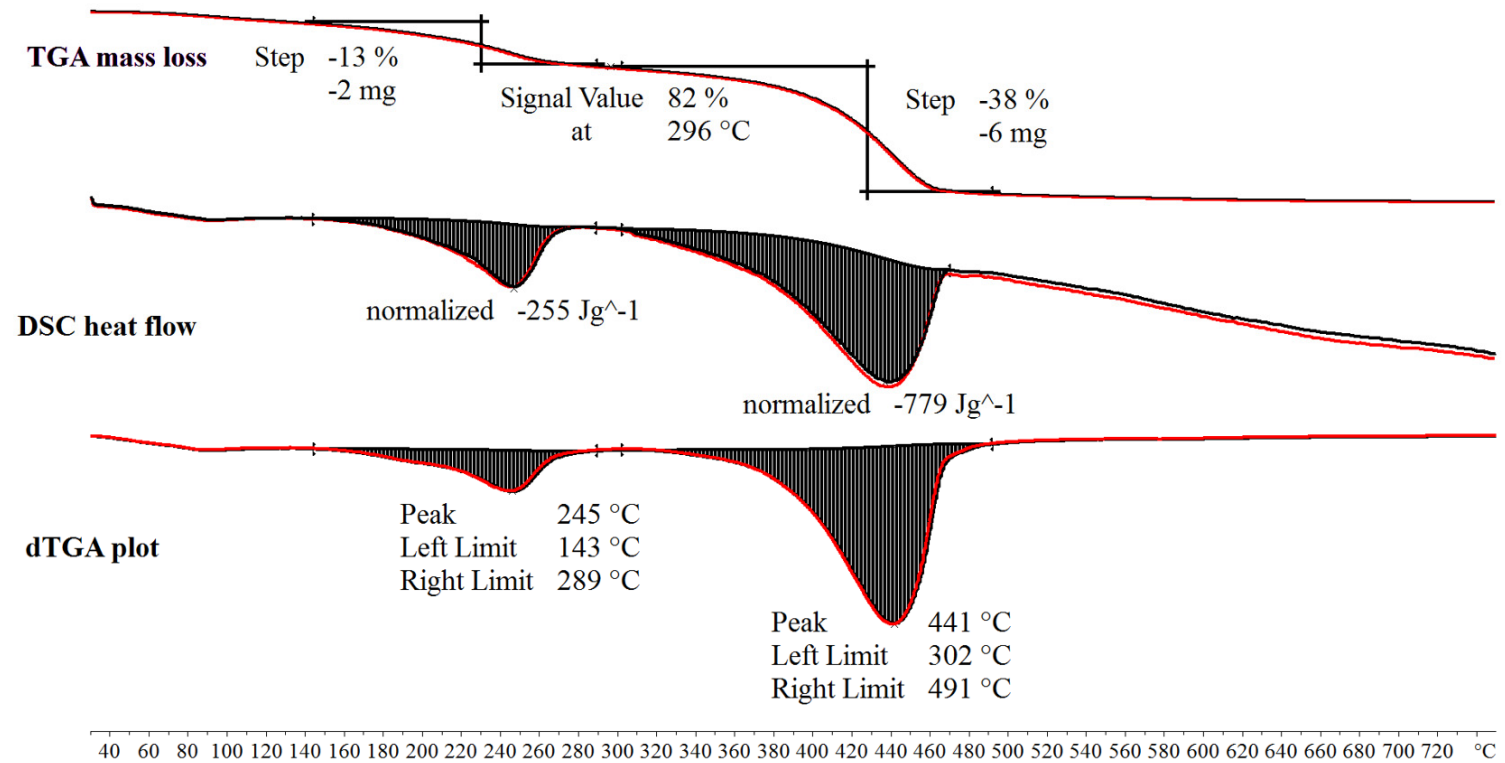

\section{Temperature $\left({ }^{\circ} \mathrm{C}\right)$}

Figure 3. Thermogravimetric analysis (TGA), differential scanning calorimetry (DSC) and differential thermogravimetric analysis (dTGA) thermal decomposition data of $\mathrm{MgCO}_{3} \cdot \mathrm{xH}_{2} \mathrm{O}$ under an $\mathrm{N}_{2}$ purge gas.

3.1. Quantifying the Enthalpy from Decomposition Resulting in the Loss of $\mathrm{H}_{2} \mathrm{O}$ and $\mathrm{CO}_{2}$ Using RGA, TGA and DSC Data

To understand which gases were being released from the $\mathrm{MgCO}_{3} \cdot \mathrm{xH}_{2} \mathrm{O}$ sample as it was decomposed (charged), the sample was thermally decomposed in a TGA with attached RGA. Figure 4 shows the results from the TGA decomposition of $\mathrm{MgCO}_{3} \cdot \mathrm{xH}_{2} \mathrm{O}$ within a TA Instruments Discovery TGA with attached MKS Cirrus 2 RGA, the red plot shows the TGA mass loss data, the green plot is the differential TGA mass loss data, the grey plot is the ion current produced by the emission of $\mathrm{CO}_{2}(44 \mathrm{amu})$ from the $\mathrm{MgCO}_{3} \cdot \mathrm{H}_{2} \mathrm{O}$ and the blue plot is the ion current produced by the emission of $\mathrm{H}_{2} \mathrm{O}(18 \mathrm{amu})$ from the $\mathrm{MgCO}_{3} \cdot \mathrm{xH}_{2} \mathrm{O}$. 


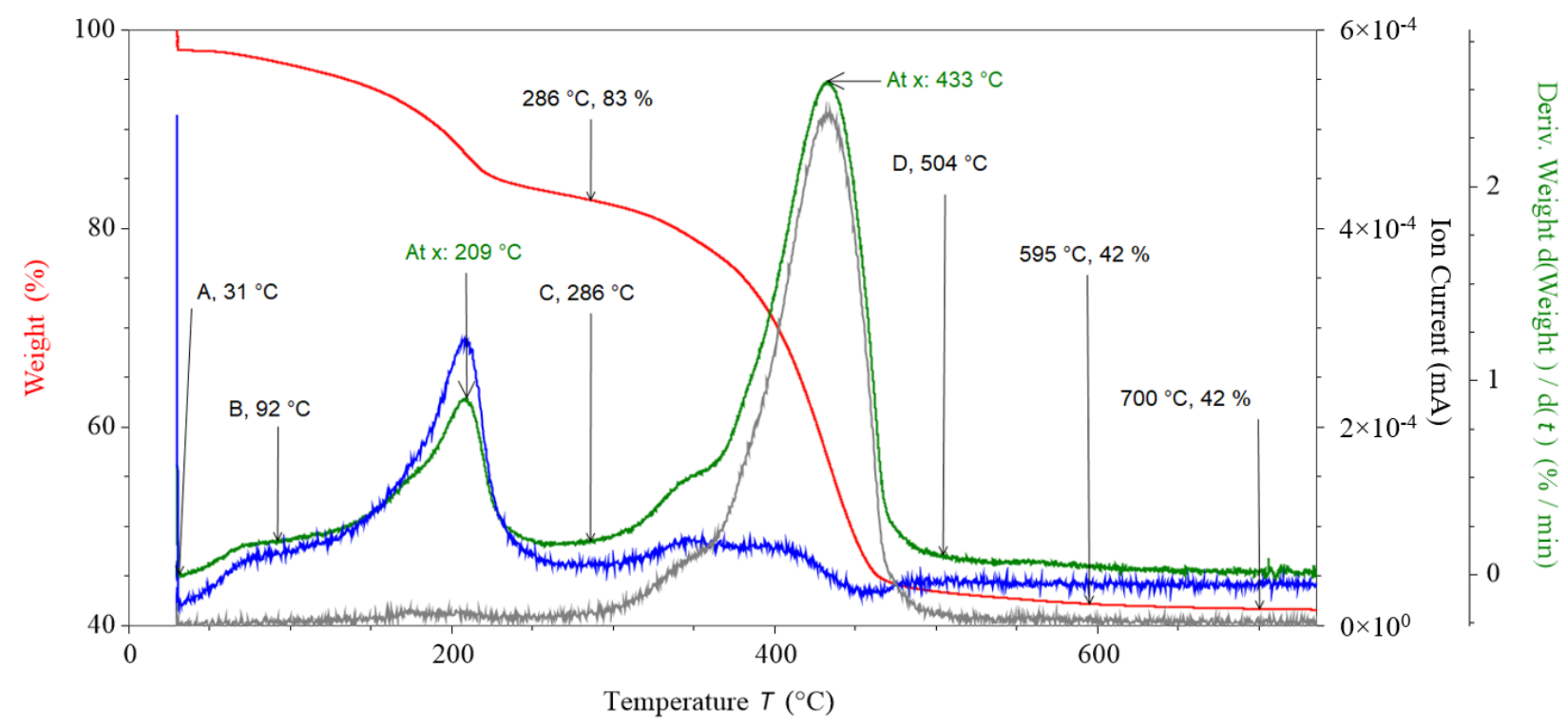

Figure 4. TGA, dTGA and residual gas analyser (RGA) thermal decomposition data of $\mathrm{MgCO}_{3} \cdot \mathrm{xH}_{2} \mathrm{O}$ (red plot = TGA mass loss data, blue plot = ion current produced from water emission, grey plot = ion current produced from $\mathrm{CO}_{2}$ emission, green plot $=$ derivative of TGA mass loss data).

\subsubsection{Peak One Analysis}

The first decomposition step was at a low temperature $\left(73^{\circ} \mathrm{C}\right.$ peak temperature). The mass loss of peak one and peak two overlapped. To quantify the mass loss of peak one, the start of peak one was assumed to be the start of the peak on the derivative mass loss (indicated by A on Figure 4) of the mass loss, and the end of the mass loss was assumed to be the lowest point of the derivative after the peak of the derivative mass loss (indicated by $B$ on Figure 4). A, B, C and D on Figure 4 are for indicative purposes only, and the values they point to are the average values used in the analysis. Using this methodology, the average mass loss for peak one was calculated as $1.7 \%$. Due to the low temperature range this initial mass loss was likely due to loosely bound water on the surface of the $\mathrm{MgCO}_{3} \cdot \mathrm{xH}_{2} \mathrm{O}$; this was supported by a peak in the $18 \mathrm{amu}\left(\mathrm{H}_{2} \mathrm{O}\right) \mathrm{RGA}$ data, which coincided with the differential mass data.

\subsubsection{Peak Two and Three Analysis}

The second mass loss peaked at an average of $208^{\circ} \mathrm{C}\left(209^{\circ} \mathrm{C}\right.$ stamped on Figure 4$)$ and left $83 \%$ of mass remaining after this second decomposition step. The average end of peak two was calculated as $286^{\circ} \mathrm{C}$ (location C on Figure 4). The trend in the $\mathrm{H}_{2} \mathrm{O}$ RGA data followed the same trend as the dTGA data for the second mass loss peak. At the same temperature there was no peak in the $\mathrm{CO}_{2}$ RGA data, indicating that the mass loss from the $\mathrm{MgCO}_{3} \cdot \mathrm{xH}_{2} \mathrm{O}$ was due to water loss and not $\mathrm{CO}_{2}$ loss.

Peak three was calculated to be between location $C$ and location D on Figure 4. The $\mathrm{CO}_{2}$ RGA data followed the same trend as the dTGA data for the third mass loss peak (average peak temperature of $433{ }^{\circ} \mathrm{C}$ ); at the same point there was a smaller peak in the $\mathrm{H}_{2} \mathrm{O}$ RGA data. These data indicate that the mass loss from the third peak was due to the loss of mainly $\mathrm{CO}_{2}$ with some $\mathrm{H}_{2} \mathrm{O}$. This showed that only the third decomposition step of $\mathrm{MgCO}_{3} \cdot \mathrm{xH}_{2} \mathrm{O}$ was due to $\mathrm{MgCO}_{3}$ decomposition (i.e., $\mathrm{CO}_{2}$ loss). The $\mathrm{H}_{2} \mathrm{O}$ RGA data increased at the same temperature that $\mathrm{CO}_{2}$ was released, suggesting that the reason why there was still $\mathrm{H}_{2} \mathrm{O}$ present when the $\mathrm{CO}_{2}$ was released was not due to the kinetics of the decomposition but due to the sample requiring elevated temperatures to remove the $\mathrm{CO}_{2}$ and also the remaining $\mathrm{H}_{2} \mathrm{O}$.

Further analysis of the data for peak three was conducted. First, the average normalised enthalpy from peak three was calculated as $923 \mathrm{~J} / \mathrm{g}$. This value was not the 
enthalpy due to $\mathrm{MgCO}_{3}$ decomposition. This normalised value was the enthalpy that could be released if $\mathrm{MgO}$ was reversed back to $\mathrm{MgCO}_{3} \cdot \mathrm{xH}_{2} \mathrm{O}$. This would require the use of both $\mathrm{CO}_{2}$ and $\mathrm{H}_{2} \mathrm{O}$, making the reverse process more complicated than only an $\mathrm{MgO}$ carbonation to $\mathrm{MgCO}_{3}$. Reversing this process may require the use of $\mathrm{H}_{2} \mathrm{O}$ and $\mathrm{CO}_{2}$ simultaneously. Adding $\mathrm{H}_{2} \mathrm{O}$ and $\mathrm{CO}_{2}$ to $\mathrm{MgO}$ may result in $\mathrm{Mg}(\mathrm{OH})_{2}$ and not $\mathrm{MgCO}_{3}$ as required, so careful control of the reactions may be required.

\subsubsection{Separating the Decomposition Enthalpy of $\mathrm{H}_{2} \mathrm{O}$ and $\mathrm{CO}_{2}$}

A further analysis of the data was conducted to evaluate the separate mass loss and enthalpy that was due to $\mathrm{H}_{2} \mathrm{O}$ loss and $\mathrm{CO}_{2}$ loss for all three peaks. Table 1 shows the values calculated and measured for this analysis. Two different methodologies were used for this analysis. Both methodologies used RGA, TGA and DSC data.

Table 1. $\mathrm{MgCO}_{3} \cdot \mathrm{xH}_{2} \mathrm{O}$ TGA, RGA and DSC decomposition analysis.

\begin{tabular}{|c|c|}
\hline Variable and Description of Calculation if Appropriate & Value \\
\hline $\begin{array}{l}\text { Mass loss due to } \mathrm{H}_{2} \mathrm{O} \text { loss from peak three (uses RGA data to distinguish between } \\
\qquad \mathrm{H}_{2} \mathrm{O} \text { and } \mathrm{CO}_{2} \text { loss (\%)) }\end{array}$ & $6.7 \%$ \\
\hline Mass loss due to $\mathrm{H}_{2} \mathrm{O}$ loss from peaks one + two + three $(\%)$ & $22.4 \%$ \\
\hline Mass loss due to $\mathrm{CO}_{2}$ loss from peak three $(\%)$ & $32.7 \%$ \\
\hline Percentage of peak three due to $\mathrm{CO}_{2}$ loss & $83 \%$ \\
\hline Peak three enthalpy $(\mathrm{J} / \mathrm{g})$ & $778.4 \mathrm{~J} / \mathrm{g}$ \\
\hline $\begin{array}{l}\text { Enthalpy from peak three due to } \mathrm{CO}_{2} \text { loss (calculated assuming } \mathrm{H}_{2} \mathrm{O} \text { and } \mathrm{CO}_{2} \\
\text { enthalpy per unit mass loss are equal and using mass loss as the proportionality) }\end{array}$ & $645.9 \mathrm{~J} / \mathrm{g}$ \\
\hline Percentage of sample that is $\mathrm{MgCO}_{3}(\%)$ (assumes $\mathrm{CO}_{2}$ loss is from $\mathrm{MgCO}_{3}$ ) & $62.7 \%$ \\
\hline $\begin{array}{c}\text { Normalised enthalpy from peak three due to } \mathrm{CO}_{2} \text { loss (calculated assuming } \mathrm{H}_{2} \mathrm{O} \\
\text { and } \mathrm{CO}_{2} \text { enthalpy per unit mass loss are equal and using mass loss as the } \\
\text { proportionality)-Method } 1\end{array}$ & $1030 \mathrm{~J} / \mathrm{g}$ \\
\hline $\begin{array}{l}\text { Enthalpy from peak three due to } \mathrm{H}_{2} \mathrm{O} \text { loss (calculated assuming enthalpy per unit } \\
\text { mass loss for } \mathrm{H}_{2} \mathrm{O} \text { is the same for all peaks. The enthalpy per unit mass loss is } \\
\text { calculated from peak one + two mass loss and enthalpy) }\end{array}$ & $117.6 \mathrm{~J} / \mathrm{g}$ \\
\hline $\begin{array}{l}\text { Enthalpy from peak three due to } \mathrm{CO}_{2} \text { loss (calculated assuming enthalpy per unit } \\
\text { mass loss for } \mathrm{H}_{2} \mathrm{O} \text { is the same for all peaks. The enthalpy per unit mass loss is } \\
\text { calculated from peak one + two mass loss and enthalpy) }\end{array}$ & $660.8 \mathrm{~J} / \mathrm{g}$ \\
\hline $\begin{array}{l}\text { Normalised enthalpy from peak three due to } \mathrm{CO}_{2} \text { loss (calculated assuming } \mathrm{H}_{2} \mathrm{O} \\
\text { enthalpy per unit mass loss is the same for all peaks. The enthalpy per unit mass } \\
\text { loss is calculated from peak one + two mass loss and enthalpy)-Method } 2\end{array}$ & $1054 \mathrm{~J} / \mathrm{g}$ \\
\hline
\end{tabular}

The first methodology assumed that the enthalpy per mass loss from $\mathrm{H}_{2} \mathrm{O}$ and $\mathrm{CO}_{2}$ within peak three was equal. The second method assumed that the enthalpy per unit mass loss from $\mathrm{H}_{2} \mathrm{O}$ was the same for all peaks (i.e., peaks one, two and three).

The $\mathrm{H}_{2} \mathrm{O}$ mass loss from peak three was found to be $6.7 \%$, the total average $\mathrm{H}_{2} \mathrm{O}$ mass loss from the $\mathrm{MgCO}_{3} \cdot \mathrm{xH}_{2} \mathrm{O}$ sample was $22.4 \%$. The $\mathrm{CO}_{2}$ mass loss for peak three was $32.7 \%$, meaning the $\mathrm{CO}_{2}$ loss accounted for $83 \%$ of the mass loss in peak three. If the sample was monohydrate magnesium carbonate $\left(\mathrm{MgCO}_{3} \cdot 1 \mathrm{H}_{2} \mathrm{O}\right)$ the total expected mass loss after the $\mathrm{CO}_{2}$ and the $\mathrm{H}_{2} \mathrm{O}$ were thermally decomposed from the sample would be $61 \%$.

The average normalised enthalpy values found due to $\mathrm{CO}_{2}$ loss for peak three using methodologies one and two were $1030 \mathrm{~J} / \mathrm{g}$ and $1054 \mathrm{~J} / \mathrm{g}$, respectively. This equated to an error of $2 \%$ in the normalised enthalpy values for $\mathrm{CO}_{2}$ loss in peak three using the two different methodologies for calculation. The normalised enthalpy values calculated for the $\mathrm{CO}_{2}$ loss in peak three were the enthalpy values for the decomposition of $\mathrm{MgCO}_{3}$, and therefore should be the reversible enthalpy output when $\mathrm{MgO}$ is carbonated to $\mathrm{MgCO}_{3}$. The theoretical value for $\mathrm{MgCO}_{3}$ was $1387 \mathrm{~J} / \mathrm{g}$, the experimentally measured values were $74 \%$ and $76 \%$ of the theoretical value.

Hydromagnesite $\left(4 \mathrm{MgCO}_{3} \cdot \mathrm{Mg}(\mathrm{OH})_{2} \cdot 4 \mathrm{H}_{2} \mathrm{O}\right)$ has been suggested to have a three-step thermal decomposition that starts with the dehydration of the crystalline $\mathrm{H}_{2} \mathrm{O}$ at $<300{ }^{\circ} \mathrm{C}$, 
followed by the decomposition of the $\mathrm{Mg}(\mathrm{OH})_{2}$ at $<300{ }^{\circ} \mathrm{C}$ and finally the decomposition of $\mathrm{MgCO}_{3}$ at temperatures $>350{ }^{\circ} \mathrm{C}$ [22]. This three-step process is similar to the process of decomposition of the $\mathrm{MgCO}_{3} \cdot \mathrm{xH}_{2} \mathrm{O}$ tested in this study, however, the dehydration was shown to continue past $300{ }^{\circ} \mathrm{C}$ and also the decomposition of the $\mathrm{MgCO}_{3}$ was shown to take place below $350^{\circ} \mathrm{C}$.

The water that was present in peak three could be due to $\mathrm{MgCO}_{3} \cdot \mathrm{xH}_{2} \mathrm{O}$ water loss; however, it was also possible that there was some $\mathrm{Mg}(\mathrm{OH})_{2}$ within the $\mathrm{MgCO}_{3} \cdot \mathrm{xH}_{2} \mathrm{O}$ sample. Figure 5 shows a TGA and RGA decomposition of $\mathrm{MgCO}_{3} \cdot \mathrm{xH}_{2} \mathrm{O}$ overlaid with the decomposition of $\mathrm{Mg}(\mathrm{OH})_{2}$, showing the differential mass loss and also the $\mathrm{H}_{2} \mathrm{O}$ RGA data for both samples. The peak mass loss from the $\mathrm{Mg}(\mathrm{OH})_{2}$ sample was at $342{ }^{\circ} \mathrm{C}$. There was a peak in the $\mathrm{MgCO}_{3} \cdot \mathrm{xH}_{2} \mathrm{O}$ differential mass loss data that coincided with a mass loss in the $\mathrm{H}_{2} \mathrm{O}$ RGA data at $347^{\circ} \mathrm{C}$ for the $\mathrm{MgCO}_{3} \cdot \mathrm{xH}_{2} \mathrm{O}$ sample. This peak at $347^{\circ} \mathrm{C}$ could have been due to $\mathrm{Mg}(\mathrm{OH})_{2}$ decomposition in the sample.

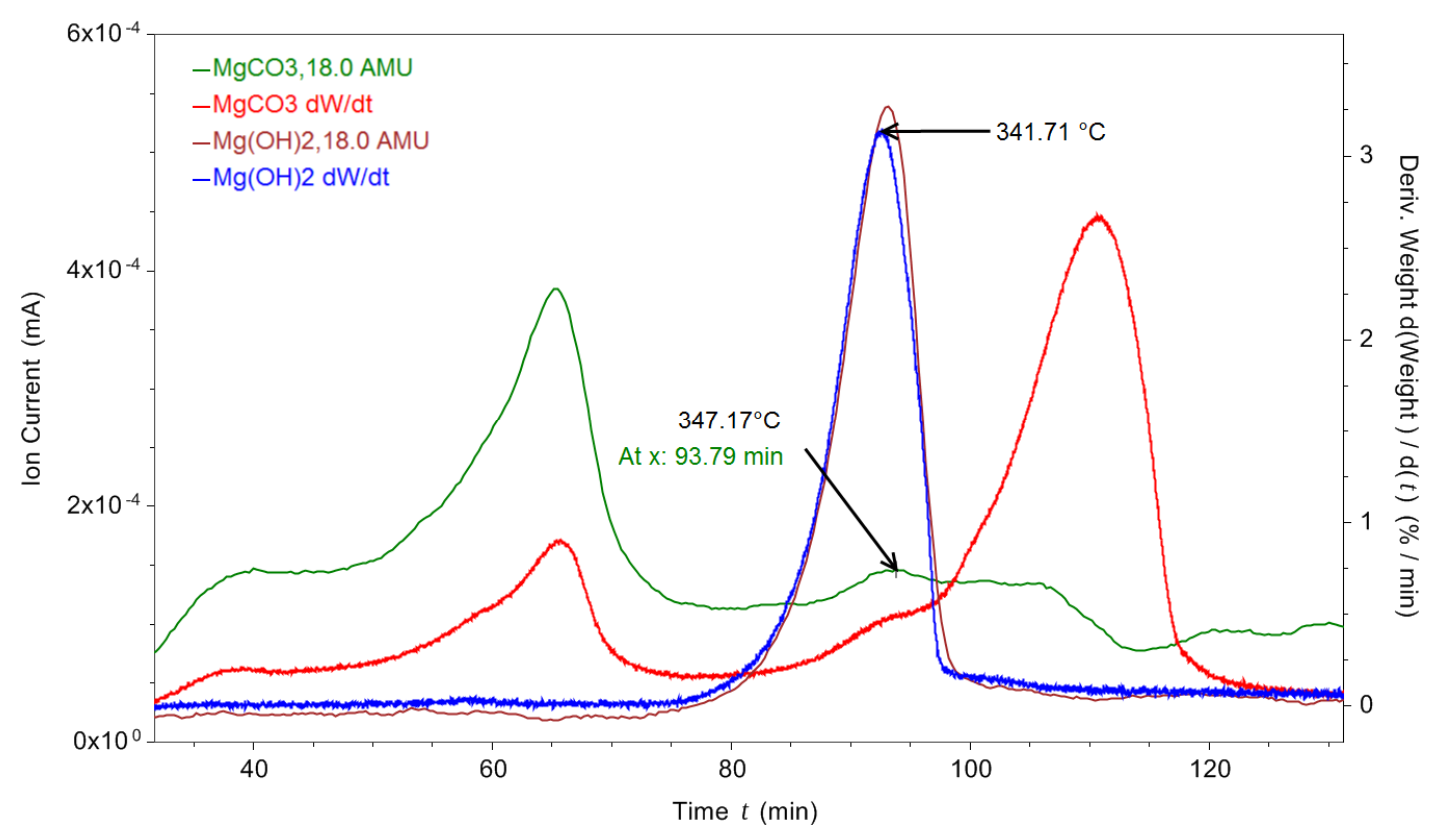

Figure 5. dTGA thermal decomposition data of $\mathrm{MgCO}_{3} \cdot \mathrm{xH}_{2} \mathrm{O}$ and $\mathrm{Mg}(\mathrm{OH})_{2}$ with the $\mathrm{RGA}$ ion current for $\mathrm{H}_{2} \mathrm{O}(18 \mathrm{amu})$ shown for both samples.

This did not have an impact on the calculated $\mathrm{CO}_{2}$ mass for the $\mathrm{MgCO}_{3} \cdot \mathrm{xH}_{2} \mathrm{O}$ decomposition as the decomposition of $\mathrm{Mg}(\mathrm{OH})_{2}$ yielded $\mathrm{MgO}$ and $\mathrm{H}_{2} \mathrm{O}$, meaning only the calculation for the amount of $\mathrm{H}_{2} \mathrm{O}$ in the starting sample $\left(\mathrm{MgCO}_{3} \cdot \mathrm{xH}_{2} \mathrm{O}\right)$ would have been impacted as some of the $\mathrm{H}_{2} \mathrm{O}$ may have been from $\mathrm{Mg}(\mathrm{OH})_{2}$. Hence, the starting material may have been $\mathrm{MgCO}_{3} \cdot \mathrm{xH}_{2} \mathrm{O}+\mathrm{Mg}(\mathrm{OH})_{2}$.

\subsection{The Decomposition of $\mathrm{MgCO}_{3} \cdot x \mathrm{H}_{2} \mathrm{O}$ in a $\mathrm{CO}_{2}$ Atmosphere}

Figure 6 shows the TGA, dTGA and DSC data for the decomposition of $\mathrm{MgCO}_{3} \cdot \mathrm{xH}_{2} \mathrm{O}$ with a $\mathrm{CO}_{2}$ purge gas. The difference between the thermal decomposition of $\mathrm{MgCO}_{3} \cdot \mathrm{xH}_{2} \mathrm{O}$ within an $\mathrm{N}_{2}$ and $\mathrm{CO}_{2}$ environment was in the third and final peak, as seen in Figure 3, which changes into three separate peaks in Figure 6 when $\mathrm{MgCO}_{3} \cdot \mathrm{xH}_{2} \mathrm{O}$ was thermally decomposed in $\mathrm{CO}_{2}$. The decomposition followed the same trend as the decomposition in an $\mathrm{N}_{2}$ environment up until $281^{\circ} \mathrm{C}$ (end of peak two). As shown in Figure 3, the $\mathrm{CO}_{2}$ decomposition peak started at $302{ }^{\circ} \mathrm{C}$, whereas in Figure 6 under a $\mathrm{CO}_{2}$ purge gas the $\mathrm{CO}_{2}$ decomposition peak started at $355^{\circ} \mathrm{C}$. 


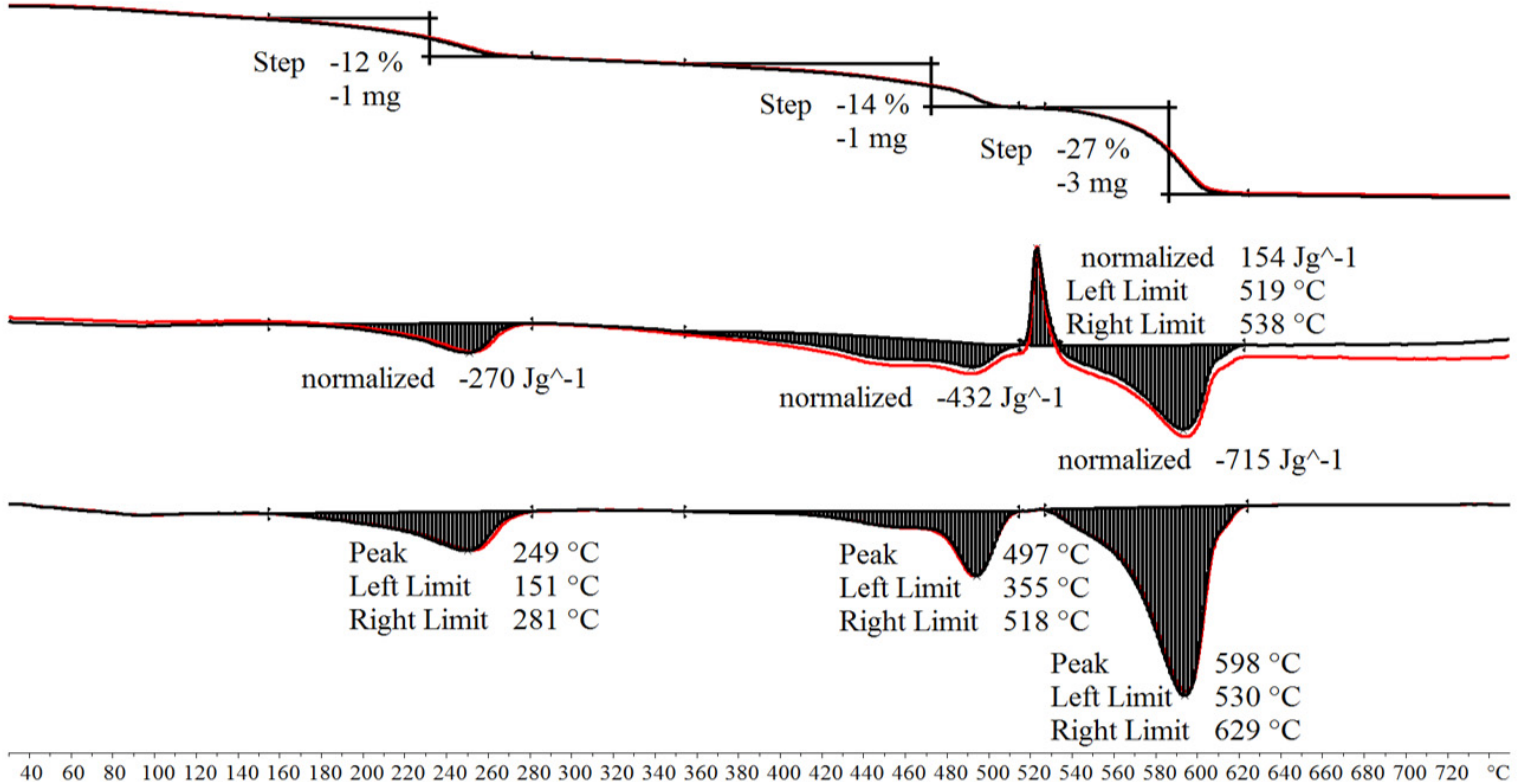

\section{Temperature $\left({ }^{\circ} \mathrm{C}\right)$}

Figure 6. TGA, DSC and dTGA thermal decomposition data of $\mathrm{MgCO}_{3} \cdot \mathrm{xH}_{2} \mathrm{O}$ under a $\mathrm{CO}_{2}$ purge gas.

$\mathrm{MgCO}_{3}$ has a theoretical turning temperature of $396^{\circ} \mathrm{C}$; the average onset point for peak three (assumed start of $\mathrm{MgCO}_{3}$ decomposition) of the $\mathrm{MgCO}_{3} \cdot \mathrm{xH}_{2} \mathrm{O}$ decomposition under a $\mathrm{N}_{2}$ purge gas was measured as $374^{\circ} \mathrm{C}$ and the average endset temperature was $467{ }^{\circ} \mathrm{C}$. This was a $93^{\circ} \mathrm{C}$ temperature range for decomposing (charging) the $\mathrm{MgCO}_{3}$. When decomposed using a $\mathrm{CO}_{2}$ purge gas the average onset and endset temperatures of the final peak were $565^{\circ} \mathrm{C}$ and $612{ }^{\circ} \mathrm{C}$. The difference between the endset of the $\mathrm{MgCO}_{3}$ using an $\mathrm{N}_{2}$ or a $\mathrm{CO}_{2}$ purge gas was $145^{\circ} \mathrm{C}$. The application requiring a TCES material with a maximum required charging temperature of $467^{\circ} \mathrm{C}$ (average endset temperature in $\mathrm{N}_{2}$ ) is likely to be different from a TCES material with a maximum required charging temperature of $612{ }^{\circ} \mathrm{C}$ (average endset temperature in $\mathrm{CO}_{2}$ ).

Analysis of the Exothermic Peak Seen in the Thermal Decomposition Peak of $\mathrm{MgCO}_{3} \cdot \mathrm{xH}_{2} \mathrm{O}$ in a $\mathrm{CO}_{2}$ Atmosphere

When the $\mathrm{MgCO}_{3} \cdot \mathrm{xH}_{2} \mathrm{O}$ sample was decomposed in $\mathrm{CO}_{2}$ there was an exothermic peak of $154 \mathrm{~J} / \mathrm{g}$ between $519^{\circ} \mathrm{C}$ and $538^{\circ} \mathrm{C}$. This exothermic peak has been observed by other authors, including N. Khan et al. [23] and Y. Sawada et al. [22]. This exothermic peak was only found when the sample gas used was $\mathrm{CO}_{2}$; however, N. Khan et al. [23] observed the peak when the sample was exposed to an $\mathrm{N}_{2}$ purge gas and when the heating rate was $18.5^{\circ} \mathrm{C} / \mathrm{min}$ or above with a sample size of 6-8 $\mathrm{mg}$. However, $\mathrm{N}$ Khan et al. [23] found that when the sample size was increased to $15-18 \mathrm{mg}$ the heating rate when the exothermic peak was evident decreased to $15{ }^{\circ} \mathrm{C} / \mathrm{min}$ [23]. The results from testing a sample of $80 \mathrm{mg}$ (approximately $340 \%$ larger than the mass used by $\mathrm{N}$ Khan et al. [23]) in the TGA/DSC, using the single differential thermal analysis (SDTA) sensor as opposed to the DSC sensor with an $\mathrm{N}_{2}$ atmosphere are presented in Figure 7. The decomposition of the $\mathrm{MgCO}_{3} \cdot \mathrm{xH}_{2} \mathrm{O}$ was found to be similar to the decomposition seen in Figure 3 with no sign of the exothermic peak, and the endset of the final peak was found to be $483^{\circ} \mathrm{C}$, which was lower than the exothermic peak seen in Figure 6. This suggests that the sample mass used did not change the decomposition of the $\mathrm{MgCO}_{3} \cdot \mathrm{xH}_{2} \mathrm{O}$ in a nitrogen atmosphere. 


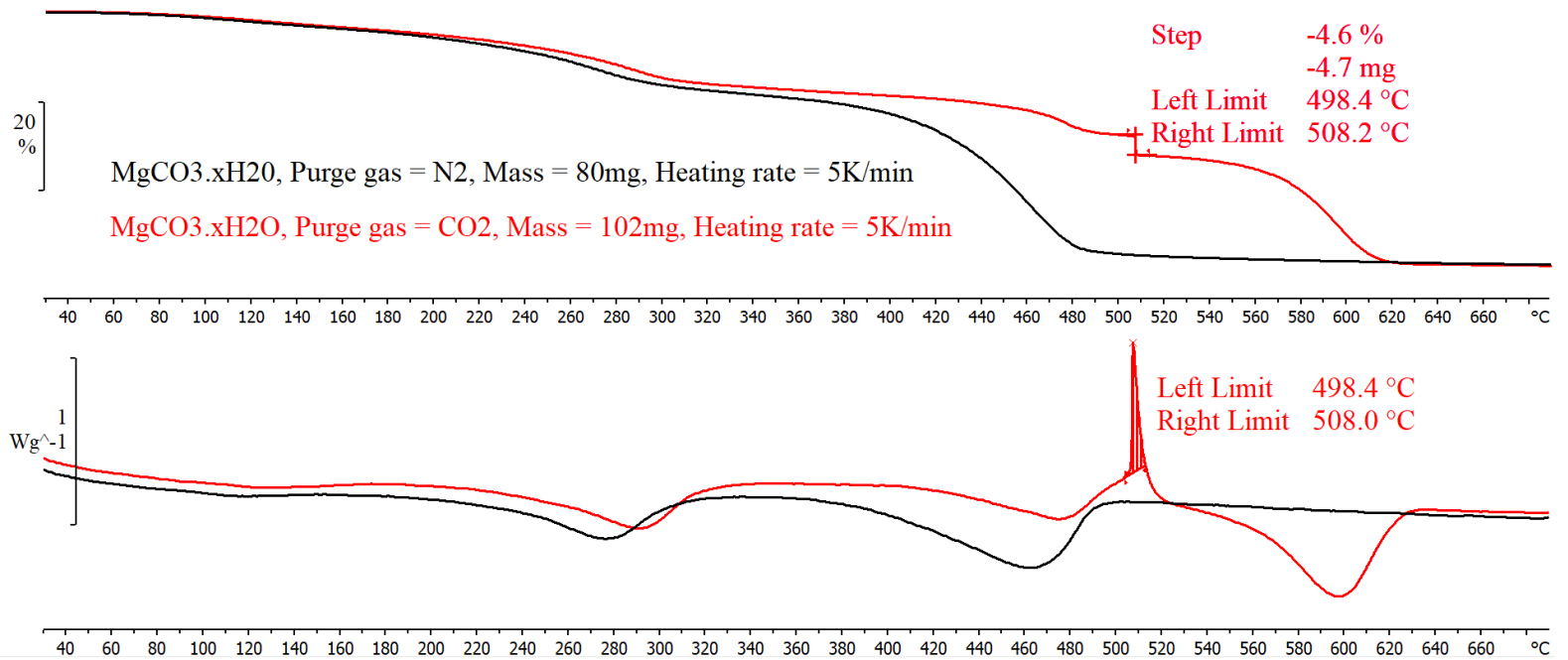

Figure 7. TGA/SDTA thermal decomposition data of $\mathrm{MgCO}_{3} \cdot \mathrm{xH}_{2} \mathrm{O}$ (Red plot: sample mass = $102 \mathrm{mg}$, purge gas $=\mathrm{CO}_{2}$; Black plot: sample mass $=80 \mathrm{mg}$, purge gas $=\mathrm{N}_{2}$ ).

This exothermic peak in Figure 6 does not correspond with a change in mass and therefore was unlikely to be due to a high-temperature carbonation. It was more likely due to a crystallisation of the sample. This is discussed further in Section 3.3.

The results for a $102 \mathrm{mg}$ sample tested in the TGA/DSC using the SDTA sensor arm and a $\mathrm{CO}_{2}$ purge gas are shown in Figure 7. The results show that at a temperature of $506^{\circ} \mathrm{C}$ there was an exothermic peak which corresponded to a mass loss of $4.6 \%$ within an $11^{\circ} \mathrm{C}$ temperature range. This suggests that the sample size did change the decomposition of the $\mathrm{MgCO}_{3} \cdot \mathrm{xH}_{2} \mathrm{O}$ when in a $\mathrm{CO}_{2}$ atmosphere.

Sawada et al. reported the heat of crystallisation as $3.4 \mathrm{kcal} / \mathrm{mol}$ [22]. From direct integration of the exothermic peak in Figure 7 the enthalpy was $154 \mathrm{~J} / \mathrm{g}(3.1 \mathrm{kcal} / \mathrm{mol})$. Assuming all of the $\mathrm{H}_{2} \mathrm{O}$ was lost and only $\mathrm{MgCO}_{3}+\mathrm{MgO}$ remained and that $62.7 \%$ of the initial sample was $\mathrm{MgCO}_{3}$ (established through the methodology described in Section 3.1.3, see Table 1 for values) but at the point of crystallisation the $\mathrm{MgCO}_{3}$ content was $55.7 \%$ of the initial starting mass (only $6.7 \%$ of the mass loss in peak three was due to $\mathrm{H}_{2} \mathrm{O}$, hence, $62.7 \%$ $(13.7 \%-6.7 \%)=55.7 \%)$, the measured heat of crystallisation became $276 \mathrm{~J} / \mathrm{g}(5.6 \mathrm{kcal} / \mathrm{mol})$. The $13.7 \%$ value was the average mass loss for peak two before the crystallisation.

Sawada et al. stated that the heat of crystallisation of $\mathrm{MgCO}_{3}$ results in the decomposition of $\mathrm{MgCO}_{3}$ and releases $\mathrm{CO}_{2}$ [22]; however, at the point of the exothermic peak there was no change in mass seen in Figure 7 , meaning that the heat of crystallisation of the $\mathrm{MgCO}_{3}$ may have allowed the decomposition of the $\mathrm{MgCO}_{3}$ to take place, but at some time after the crystallisation, not concurrent with the crystallisation. If the crystallisation and the resulting decomposition of $\mathrm{MgCO}_{3}$ took place simultaneously, first, there would be a change in mass at the same point as the exothermic peak, and the heat flow seen from the DSC data would be a combination of the heat of crystallisation $\left(\Delta \mathrm{H}_{\text {crys }}\right)$ (exothermic) and the heat of decomposition $\left(\Delta \mathrm{H}_{\text {decomp }}\right)$ (endothermic). Meaning the measured enthalpy of $154 \mathrm{~J} / \mathrm{g}=\left(\Delta \mathrm{H}_{\text {crys }}\right)+\left(\Delta \mathrm{H}_{\text {decomp }}\right)$ would result in the $\left(\Delta \mathrm{H}_{\text {crys }}\right)$ enthalpy being higher than the measured value, making the value measured after normalisation $(5.6 \mathrm{kcal} / \mathrm{mol})$ even further away from the value of $3.4 \mathrm{kcal} / \mathrm{mol}$. These two points suggest that the crystallisation of $\mathrm{MgCO}_{3}$ took place and then further decomposition proceeded. It is suggested to be a further decomposition and not the start of the $\mathrm{MgCO}_{3}$ decomposition, as from Table 1 it can be seen that only $6.7 \%$ of the final peak was due to $\mathrm{H}_{2} \mathrm{O}$ loss, and from Figure 6 it is seen that there was already a $14 \%$ (average mass loss value of $13.7 \%$ ) mass loss before the crystallisation peak, meaning $7.3 \%$ (average $7 \%$ ) of the mass loss before the crystallisation must have been from $\mathrm{MgCO}_{3}$ decomposition. 
The material used in the $\mathrm{CO}_{2}$ atmosphere experiments was the same as that used for the $\mathrm{N}_{2}$ atmosphere tests. The average total enthalpy for the third step was $976 \mathrm{~J} / \mathrm{g}$ (Figure 6). Using method one, described in Section 3.1.3, to calculate the normalised enthalpy from the loss of $\mathrm{CO}_{2}$ a value of $810 \mathrm{~J} / \mathrm{g}$ was determined. After normalising this value, the decomposition enthalpy for $\mathrm{MgCO}_{3}$ under a $\mathrm{CO}_{2}$ purge gas was $1291 \mathrm{~J} / \mathrm{g}$. Using method two, described in Section 3.1.3, the average enthalpy from the loss of $\mathrm{CO}_{2}$ was $862 \mathrm{~J} / \mathrm{g}$ and after normalisation this value became $1375 \mathrm{~J} / \mathrm{g}$. The values determined using calculation methods one and two with the experimentally measured data were $93 \%$ and $99 \%$ of the theoretical value, respectively. This analysis assumed that none of the $\mathrm{CO}_{2}$ gas stream reacted with the sample while it was decomposing. A completely new analysis using RGA data was not conducted using a $\mathrm{CO}_{2}$ purge gas on the $\mathrm{MgCO}_{3} \cdot \mathrm{xH}_{2} \mathrm{O}$ sample because the TA Instruments TGA was not configured to allow a $\mathrm{CO}_{2}$ purge gas.

\subsection{The Decomposition of $\mathrm{MgCO}_{3} \cdot x \mathrm{H}_{2} \mathrm{O}$ Using an in situ DRIFTS Technique}

An FT-IR can be used to measure how a sample absorbs light over a range of wavelengths. The absorption pattern can help identify the chemical composition of the sample. An FT-IR scan of a sample of the base material used for these experiments revealed that the material matched closest to hydromagnesite $\left(\mathrm{Mg}_{5}\left(\mathrm{CO}_{3}\right)_{4}(\mathrm{OH})_{2} \cdot 4 \mathrm{H}_{2} \mathrm{O}\right)(83 \%$ match), with nesquehonite $\left(\mathrm{MgCO}_{3} \cdot 3 \mathrm{H}_{2} \mathrm{O}\right)$ and magnesium carbonate having a match of $71 \%$ and $64 \%$, respectively. The pronounced peak at around $3000 \mathrm{~cm}^{-1}$, which was found on the hydromagnesite spectra, was also found on the run of the $\mathrm{MgCO}_{3} \cdot \mathrm{xH}_{2} \mathrm{O}$ sample. This further confirmed the presence of $\mathrm{H}_{2} \mathrm{O}$ in the sample.

Figure 8 shows DRIFTS FT-IR data for the in situ thermal decomposition of $\mathrm{MgCO}_{3} \cdot \mathrm{xH}_{2} \mathrm{O}$ under an $\mathrm{N}_{2}$ purge gas and a $5 \mathrm{~K} / \mathrm{min}$ ramp rate. The data show two main changes in the absorbance data that occurred at $46 \mathrm{~min}$ for wavenumber $3000 \mathrm{~cm}^{-1}$ and $85 \mathrm{~min}$ for wavenumber $1505 \mathrm{~cm}^{-1}$, which corresponded to $254{ }^{\circ} \mathrm{C}$ and $445{ }^{\circ} \mathrm{C}$, respectively. The first step change at $254{ }^{\circ} \mathrm{C}$ was established to be the release of $\mathrm{H}_{2} \mathrm{O}$ from the TGA and RGA data. The wavenumber of $3000 \mathrm{~cm}^{-1}$ was known to correspond to $\mathrm{H}_{2} \mathrm{O}$ adsorption. The FT-IR data supported the conclusion that the first mass loss from the $\mathrm{MgCO}_{3} \cdot \mathrm{xH}_{2} \mathrm{O}$ was due to water loss. The loss that was associated to a wavenumber of $1505 \mathrm{~cm}^{-1}$ occurred at $445^{\circ} \mathrm{C}$, which corresponded to the TGA/DSC data temperature of $441^{\circ} \mathrm{C}$. This was predominantly due to the $\mathrm{CO}_{2}$ loss. The wavenumbers that are associated with $\mathrm{H}_{2} \mathrm{O}$ IR adsorption had a loss in absorbance at around the same time as the loss from wavenumber $1505 \mathrm{~cm}^{-1}$ at $85 \mathrm{~min}\left(445^{\circ} \mathrm{C}\right)$ and further confirmed that the $\mathrm{MgCO}_{3} \cdot \mathrm{xH}_{2} \mathrm{O}$ lost $\mathrm{H}_{2} \mathrm{O}$ at the same temperature as when $\mathrm{CO}_{2}$ loss occurred.

The DRIFTS FT-IR decomposition of $\mathrm{MgCO}_{3} \cdot \mathrm{xH}_{2} \mathrm{O}$ under a $\mathrm{CO}_{2}$ purge gas is shown in Figure 9, which is clearly different from the profile shown in Figure 8. This corroborated the TGA and DSC data shown in Figure 6, which also indicated a different decomposition of $\mathrm{MgCO}_{3} \cdot \mathrm{xH}_{2} \mathrm{O}$ when decomposed in a $\mathrm{CO}_{2}$ atmosphere. The gaps in the spectrum data were due to the wavenumbers that became saturated due to the use of $\mathrm{CO}_{2}$ as the purge gas; these saturated wavenumbers were blanked out to allow for analysis of the remaining data. At $124 \min \left(642{ }^{\circ} \mathrm{C}\right)$ in Figure 9 there is a change in the absorption at wavenumber $1495 \mathrm{~cm}^{-1}$, which was due to the loss of $\mathrm{CO}_{2}$ from the $\mathrm{MgCO}_{3} \cdot \mathrm{xH}_{2} \mathrm{O}$ sample. This agreed with the TGA/DSC data presented in Figure 6, which show that the decomposition of $\mathrm{MgCO}_{3} \cdot \mathrm{xH}_{2} \mathrm{O}$ completed at a higher temperature in $\mathrm{CO}_{2}$ atmosphere compared to an $\mathrm{N}_{2}$ atmosphere. 


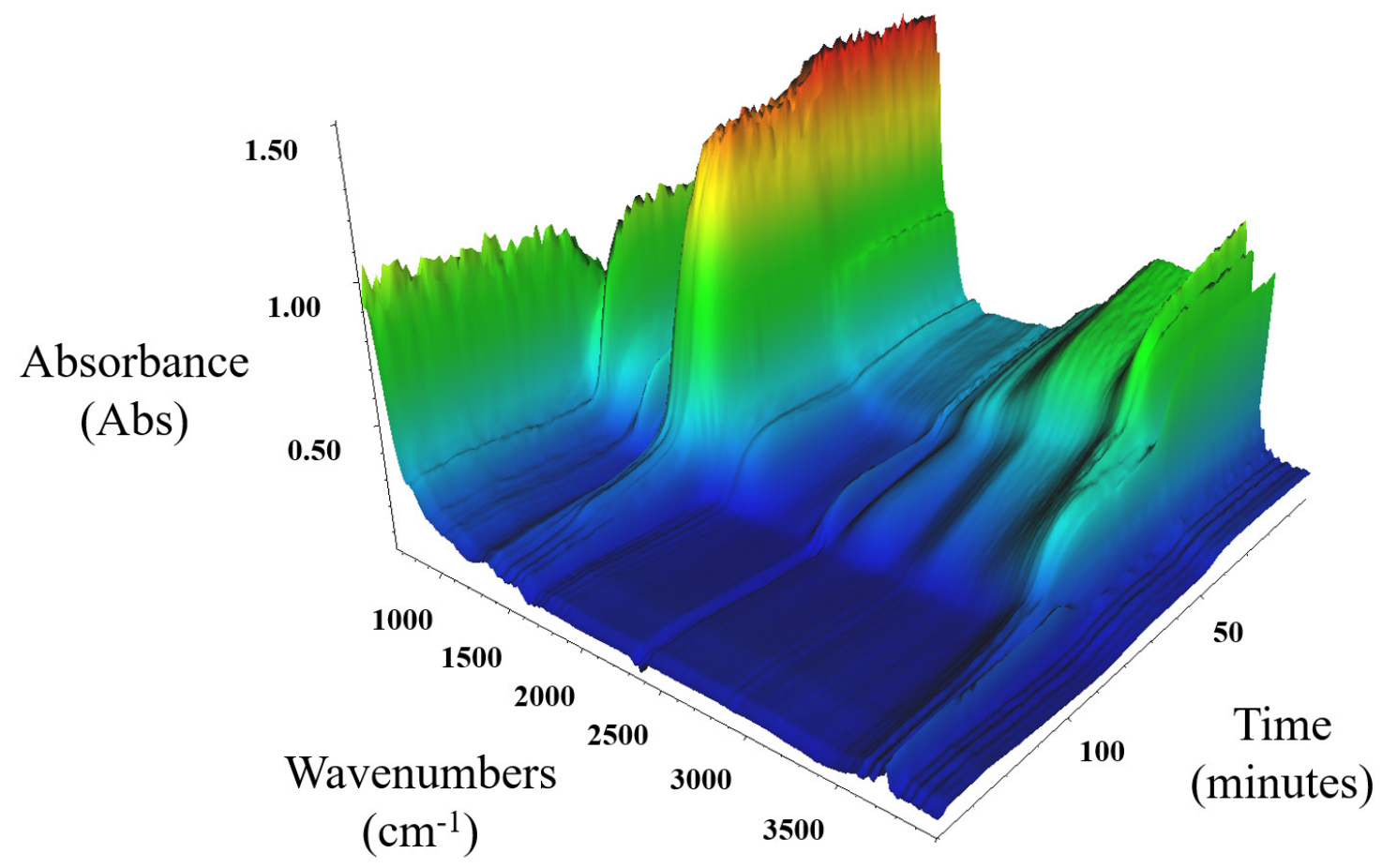

Figure 8. DRIFTS FT-IR series decomposition data for $\mathrm{MgCO}_{3} \cdot \mathrm{xH}_{2} \mathrm{O}$ under an $\mathrm{N}_{2}$ purge gas and a $5 \mathrm{~K} / \mathrm{min}$ ramp rate.

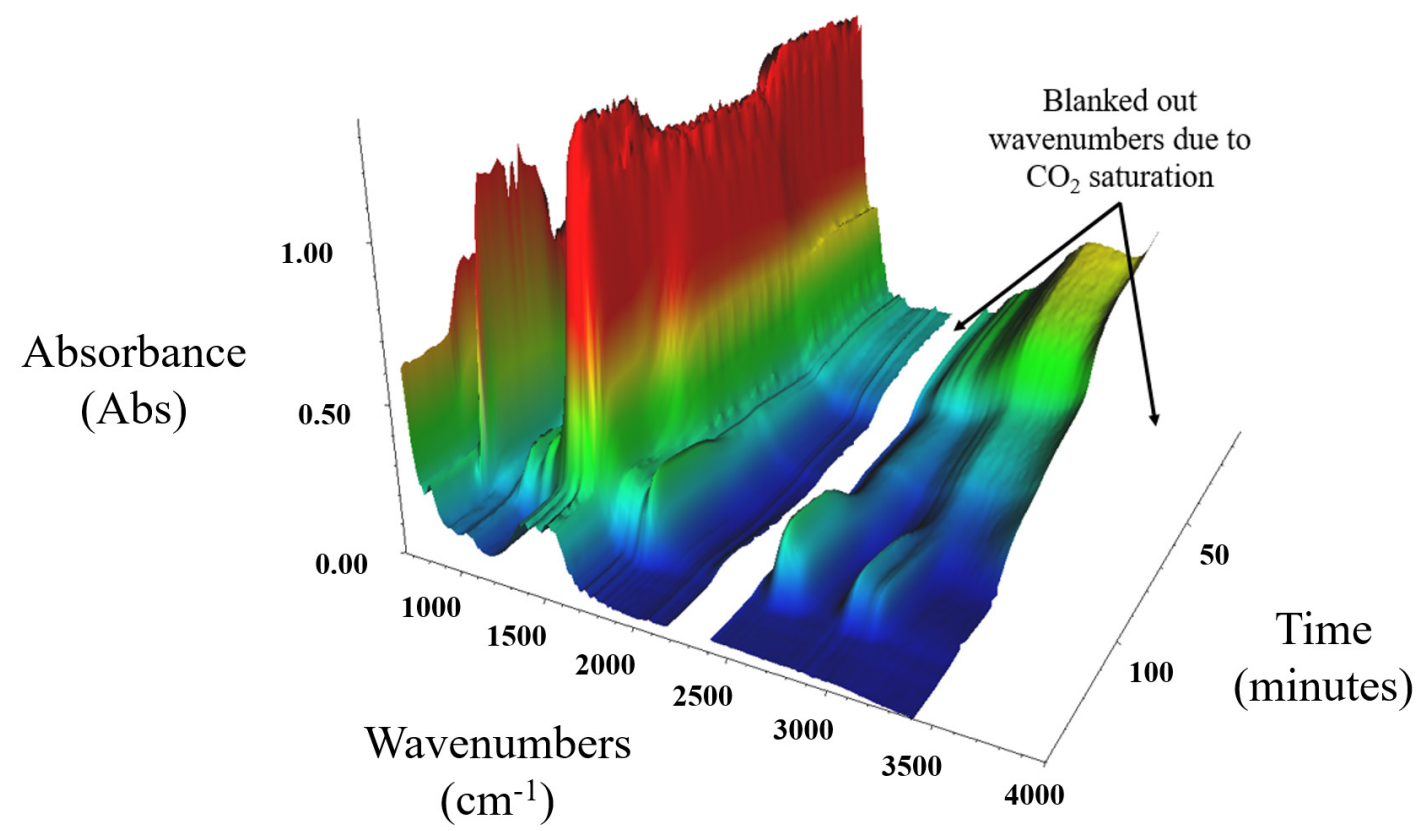

Figure 9. DRIFTS FT-IR series decomposition data for $\mathrm{MgCO}_{3} \cdot \mathrm{xH}_{2} \mathrm{O}$ under a $\mathrm{CO}_{2}$ purge gas.

At around $100 \mathrm{~min}\left(522{ }^{\circ} \mathrm{C}\right)$ in Figure 9 there is an increase in the adsorption in the $\mathrm{CO}_{2}$ range, which corresponds with the exothermic peak seen on the TGA and DSC data presented in Figure 6. This suggests that this exothermic peak may have been due to carbonation of the $\mathrm{MgCO}_{3} \cdot \mathrm{xH}_{2} \mathrm{O}$ sample. There is no increase in mass shown on the TGA/DSC data presented in Figure 6, which suggests that instead of a carbonation there was a change in the crystal structure of the material resulting in an exothermic heat flow and causing an increased absorption at specific wavenumbers, and this crystal structure change did not result in an increase in mass. 


\subsection{The Charging Kinetics and Charging Power of $\mathrm{MgCO}_{3} \cdot x \mathrm{H}_{2} \mathrm{O}$}

The charging of TCES materials (i.e., $\mathrm{MgCO}_{3}$ ) for industrial applications may take place over a short amount of time. For this reason, experimental investigations were undertaken to understand how $\mathrm{MgCO}_{3} \cdot \mathrm{xH}_{2} \mathrm{O}$ decomposes, and therefore charges, with different heating rates. The amount of thermal energy that can be stored when using $\mathrm{MgCO}_{3} \cdot \mathrm{xH}_{2} \mathrm{O}$ as a storage material with different isothermal charge temperatures was investigated experimentally.

To assess the rate of charging of $\mathrm{MgCO}_{3} \cdot \mathrm{xH}_{2} \mathrm{O}$, a TGA with attached RGA was used. The samples were heated at $200{ }^{\circ} \mathrm{C} / \mathrm{min}$ until the required isothermal temperatures were reached. The measurements were used to provide an understanding of the kinetics of the $\mathrm{MgCO}_{3} \cdot \mathrm{xH}_{2} \mathrm{O}$ decomposition, the charging rate and the overall percentage charge achieved at each temperature.

It was expected that as the selected isothermal temperature increased so would the rate of decomposition, the overall mass loss and the percentage charge.

Figure 10 shows the TGA mass loss curves for each of the different isothermal temperatures employed, the rate of mass loss and overall mass loss increases with isothermal temperature. However, when $\mathrm{MgCO}_{3} \cdot \mathrm{xH}_{2} \mathrm{O}$ was decomposed at an isothermal temperature of $500{ }^{\circ} \mathrm{C}$ the decomposition changed from the single sharp mass loss seen for the other isothermal temperatures tested. The initial mass loss had a gradient similar to the surrounding isothermal temperatures. The initial sharp rate of mass loss reduced at around $67 \%$ of mass remaining, and was followed by a slower rate of mass loss for around $100 \mathrm{~min}$, then the sample started to lose mass more rapidly again until the mass loss was complete at $175 \mathrm{~min}$.

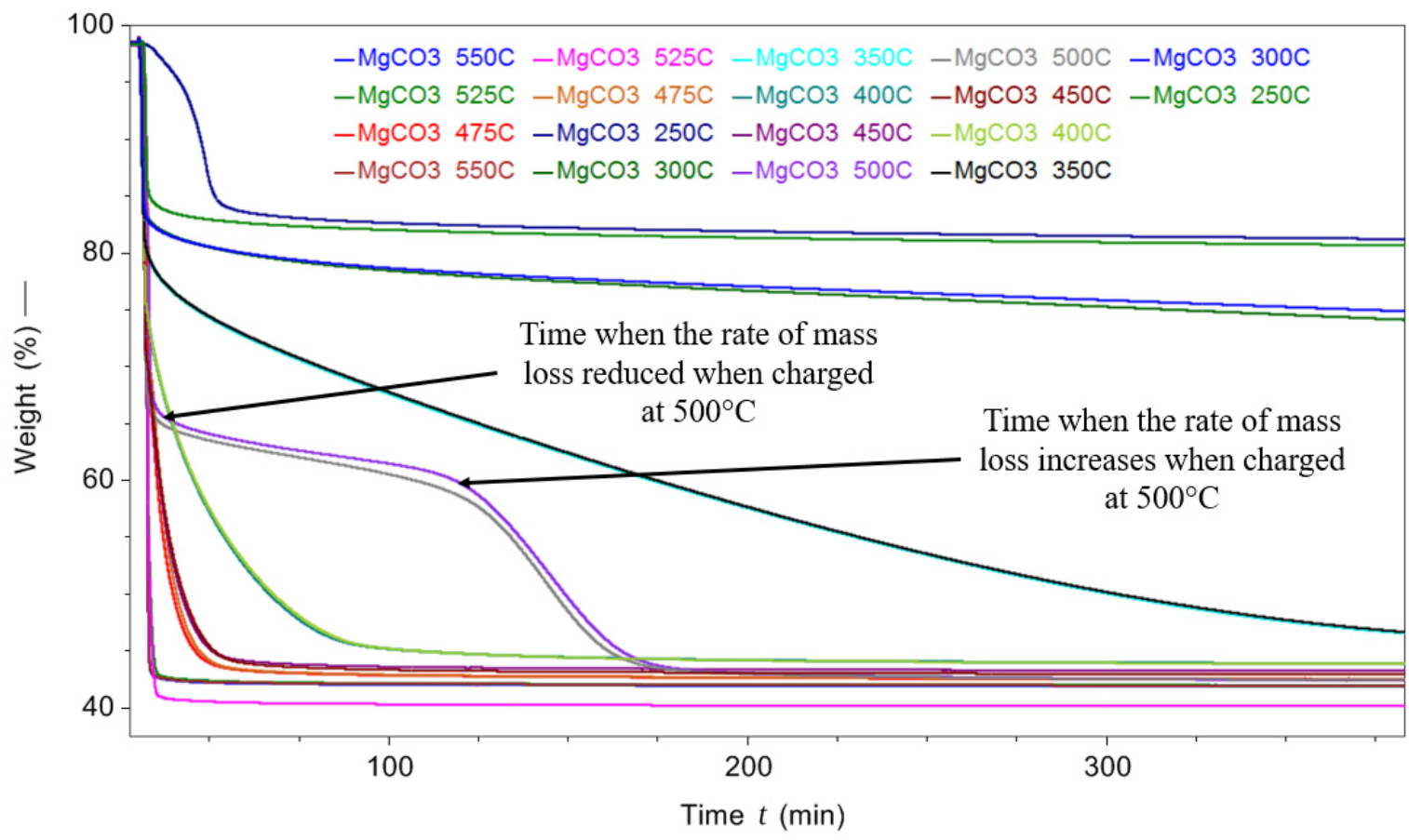

Figure 10. TGA decomposition of $\mathrm{MgCO}_{3} \cdot \mathrm{xH}_{2} \mathrm{O}$ at different isothermal temperatures from 250 to $525^{\circ} \mathrm{C}$.

The reason that increments of $25{ }^{\circ} \mathrm{C}$ in isothermal setpoint temperatures were used between $450{ }^{\circ} \mathrm{C}$ and $550{ }^{\circ} \mathrm{C}$, as opposed to $50^{\circ} \mathrm{C}$, was to produce more resolved data to hopefully provide an improved understanding of the unusual decomposition observed in the $500{ }^{\circ} \mathrm{C}$ test. The two closest temperatures $\left(475^{\circ} \mathrm{C}\right.$ and $\left.525^{\circ} \mathrm{C}\right)$ did not show the same trend as the $500{ }^{\circ} \mathrm{C}$ tests. More testing in smaller increments around $500{ }^{\circ} \mathrm{C}$ is required to fully understand this phenomenon. 
Figure 11 shows the mass loss with time as the sample was heated to and then maintained isothermally at $500{ }^{\circ} \mathrm{C}$ for different heating rates within a nitrogen atmosphere of $50 \mathrm{~K} / \mathrm{min}, 100 \mathrm{~K} / \mathrm{min}, 200 \mathrm{~K} / \mathrm{min}$ and $200 \mathrm{~K} / \mathrm{min}$ within an argon atmosphere.

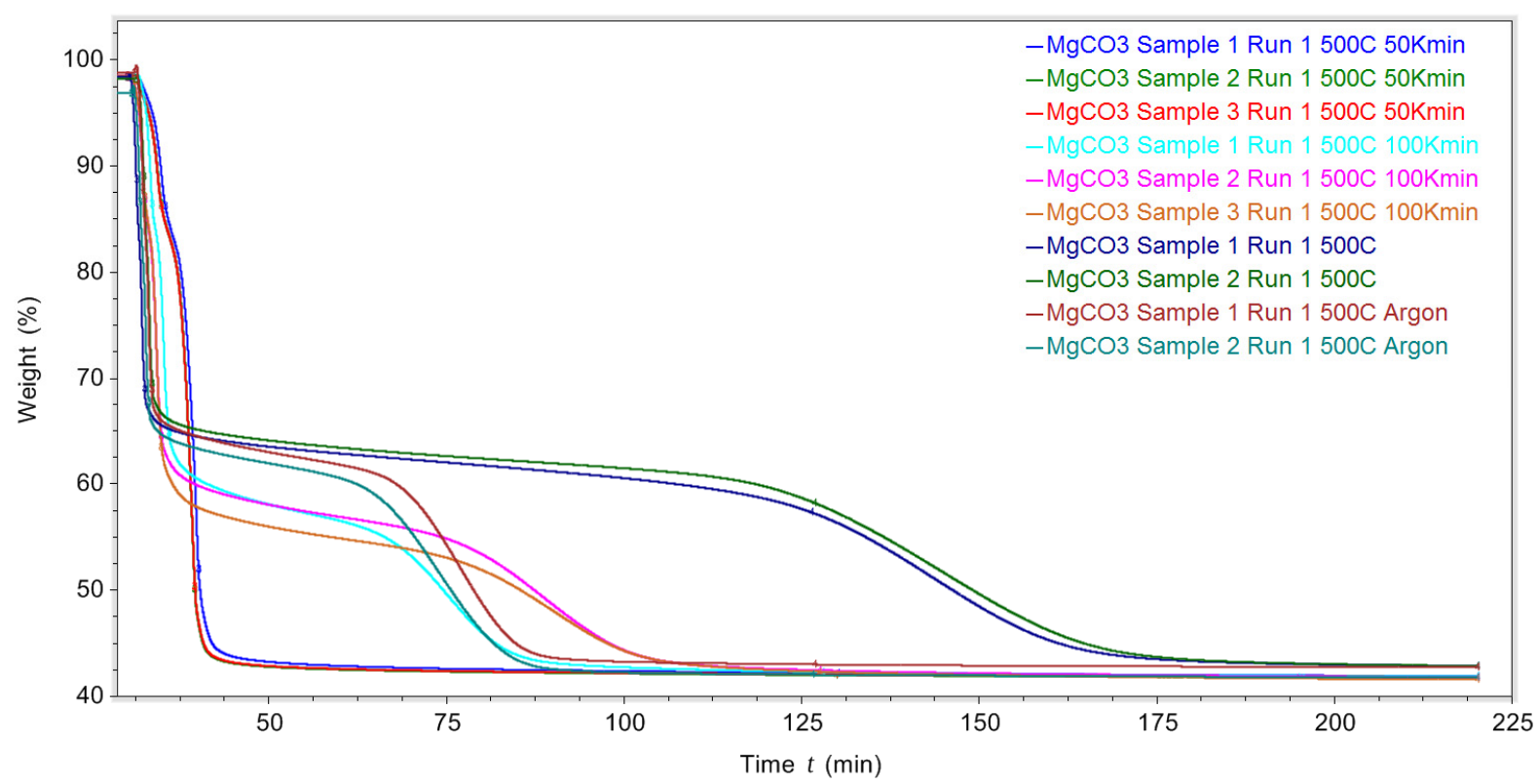

Figure 11. TGA decomposition data of $\mathrm{MgCO}_{3} \cdot \mathrm{xH}_{2} \mathrm{O}$ heated to $500{ }^{\circ} \mathrm{C}$ using different heating rates $50 \mathrm{~K} / \mathrm{min}, 100 \mathrm{~K} / \mathrm{min}$, $200 \mathrm{~K} /$ min under $\mathrm{N}_{2}$, and $200 \mathrm{~K} /$ min under argon.

The unusual thermal decomposition profile when the $\mathrm{MgCO}_{3} \cdot \mathrm{xH}_{2} \mathrm{O}$ was heated at $200 \mathrm{~K} / \mathrm{min}$ to $500^{\circ} \mathrm{C}$ was seen within an argon atmosphere as well as a nitrogen atmosphere. When using argon, the $\mathrm{MgCO}_{3} \cdot \mathrm{xH}_{2} \mathrm{O}$ reached its final mass sooner (around $100 \mathrm{~min}$ ) than when it was exposed to an $\mathrm{N}_{2}$ purge gas (around $175 \mathrm{~min}$ ). The reason for this is unknown. The reason why the decomposition of $\mathrm{MgCO}_{3} \cdot \mathrm{xH}_{2} \mathrm{O}$ was different when decomposed isothermally at $500{ }^{\circ} \mathrm{C}$, compared to surrounding isothermal temperature tests, is also unknown. Additional isothermal tests in a DSC may help to explain this change in decomposition process.

Table 2 presents an analysis of the data generated by the TGA tests shown in Figure 10. The expected enthalpy is defined as the enthalpy expected to be output from the system when discharged back to its starting state. It should be noted that the expected enthalpy values seen in Table 2 assumed that the mass loss and enthalpy were linearly related.

As the isothermal charging temperature increased the charge percentage increased, which was expected. At $400{ }^{\circ} \mathrm{C}$ the charge percentage was $96 \%$ with an expected enthalpy of $1007 \mathrm{~J} / \mathrm{g}$. The charge percentage at $550{ }^{\circ} \mathrm{C}$ was $99.1 \%$ with the corresponding expected enthalpy of $1043 \mathrm{~J} / \mathrm{g}$, the difference in enthalpy $(36 \mathrm{~J} / \mathrm{g}$ ) and charge percentage $(3.1 \%)$ suggests it may not have been beneficial to charge the $\mathrm{MgCO}_{3} \cdot \mathrm{xH}_{2} \mathrm{O}$ above $400{ }^{\circ} \mathrm{C}$ to $550^{\circ} \mathrm{C}$. The increase in enthalpy achieved $(36 \mathrm{~J} / \mathrm{g}$ ) may not offset the additional sensible enthalpy required.

As an example, assume a system was to be discharged at $320^{\circ} \mathrm{C}$ around the start of the third and largest decomposition peak (assume all the enthalpy from the reaction of $\mathrm{MgCO}_{3} \Leftrightarrow \mathrm{MgO}+\mathrm{CO}_{2}$ can be recovered $\left.(1053 \mathrm{~J} / \mathrm{g})\right)$. In this example it is more beneficial to only charge to $400{ }^{\circ} \mathrm{C}$ due to the sensible heat wasted charging the $\mathrm{MgCO}_{3}$ to $550{ }^{\circ} \mathrm{C}$. When charged to $400{ }^{\circ} \mathrm{C}$ vs. $550{ }^{\circ} \mathrm{C}$ the total net stored enthalpy (decomposition enthalpy-wasted sensible enthalpy) is $968 \mathrm{~J} / \mathrm{g}$ and $780 \mathrm{~J} / \mathrm{g}$, respectively. This is because the sensible enthalpy wasted when charged at $400{ }^{\circ} \mathrm{C}\left(80{ }^{\circ} \mathrm{C}\right.$ delta of wasted sensible enthalpy) and $550{ }^{\circ} \mathrm{C}$ $\left(220^{\circ} \mathrm{C}\right.$ delta of wasted sensible enthalpy) is approximately $85 \mathrm{~J} / \mathrm{g}$ and $273 \mathrm{~J} / \mathrm{g}$, respectively. This yields a charge/discharge efficiency or performance of $92 \%$ and $79 \%$ for charging to $400{ }^{\circ} \mathrm{C}$ and $550{ }^{\circ} \mathrm{C}$, respectively. If charge discharge efficiency is the most important metric 
to be optimised in this system, then clearly charging to $400{ }^{\circ} \mathrm{C}$ would be beneficial over charging to $550{ }^{\circ} \mathrm{C}$.

Table 2. Analysis of the charging of $\mathrm{MgCO}_{3} \cdot \mathrm{xH}_{2} \mathrm{O}$ at different isothermal set point temperatures.

\begin{tabular}{ccccc}
\hline Temperature $\left({ }^{\circ} \mathrm{C}\right)$ & Average (Charge \%) & $\begin{array}{c}\text { Average Expected } \\
\text { Enthalpy (J/g) }\end{array}$ & $\begin{array}{c}\text { Average Power } \\
\text { Input (W/kg) }\end{array}$ & $\begin{array}{c}\text { Time Taken to Achieve } \\
\text { Average Charge \% (mins/kg) }\end{array}$ \\
\hline 250 & 33 & 343 & 4 & 1604 \\
\hline 300 & 44 & 461 & 6 & 4391 \\
\hline 350 & 91 & 962 & 32 & 118 \\
\hline 400 & 96 & 1007 & 374 & 45 \\
\hline 450 & 97 & 1022 & 693 & 25 \\
\hline 475 & 98 & 1033 & 40 & 428 \\
\hline 500 & 98 & 1034 & 2686 & 7 \\
\hline 525 & 101 & 1059 & 8136 & 2 \\
\hline 50 & 99.1 & 1043 & & 42 \\
\hline
\end{tabular}

If charging input power is of importance, then switching to a higher charging temperature may be advantageous. The charging power input when charged at $400{ }^{\circ} \mathrm{C}$ and $550{ }^{\circ} \mathrm{C}$ is $142 \mathrm{~W} / \mathrm{kg}$ and $8136 \mathrm{~W} / \mathrm{kg}$, respectively. The decomposition data presented in Figure 10 was assessed to find the slope of mass loss vs. time. This slope along with the expected enthalpy values were used to calculate the average power input values shown in Table 2. If a sample had a slow decomposition process the slope and therefore calculated power input would be smaller than a sample with a faster decomposition process.

Figure 12 shows the charging power input and percentage of maximum charge against isothermal charging temperature. The green plot represents $350{ }^{\circ} \mathrm{C}$ in Figure 12. This temperature is important as $350^{\circ} \mathrm{C}$ is the temperature when the percentage charge changed from $44 \%$ at $300{ }^{\circ} \mathrm{C}$ to $91 \%$ at $350{ }^{\circ} \mathrm{C}$. If $32 \mathrm{~W} / \mathrm{kg}$ is a sufficiently high charging power for a system, $350{ }^{\circ} \mathrm{C}$ may be an ideal charging temperature. The unusual decomposition at $500{ }^{\circ} \mathrm{C}$ shown in Figure 10 is characterised in Figure 12 by a drop in power input.

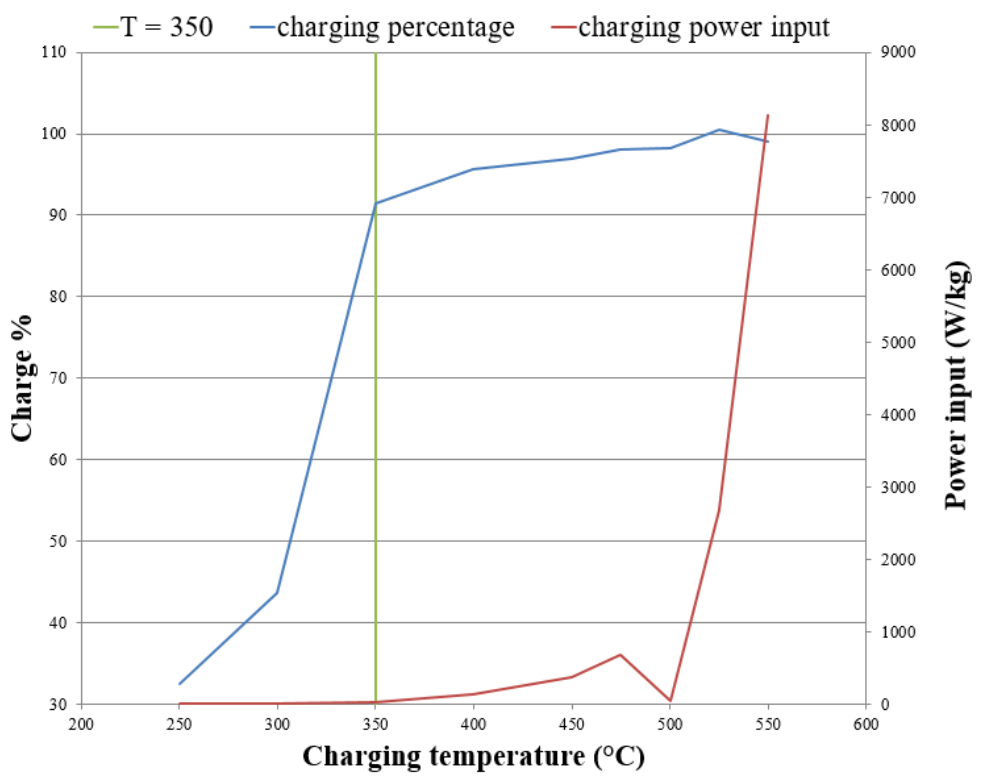

Figure 12. Graph showing the percentage charge and average power input for isothermal temperature decomposition of $\mathrm{MgCO}_{3} \cdot \mathrm{H}_{2} \mathrm{O}$. 


\subsection{High-Pressure pTGA Carbonation Tests of $\mathrm{MgCO}_{3} \cdot x \mathrm{H}_{2} \mathrm{O}$}

The discharging (carbonation process) was assessed using a high-pressure TGA (pTGA). The experiments used a treated $\mathrm{MgCO}_{3} \cdot \mathrm{xH}_{2} \mathrm{O}$ sample at several isothermal temperatures $\left(300{ }^{\circ} \mathrm{C}, 200{ }^{\circ} \mathrm{C}, 100{ }^{\circ} \mathrm{C}\right.$ and $50^{\circ} \mathrm{C}$ ) and pressures of $\mathrm{CO}_{2}$ from vacuum to 40 bar. To pre-treat each $\mathrm{MgCO}_{3} \cdot \mathrm{xH}_{2} \mathrm{O}$ sample, the reactor containing the sample was first evacuated at $30{ }^{\circ} \mathrm{C}$, then heated to a maximum of $490{ }^{\circ} \mathrm{C}$ before stabilizing at $480{ }^{\circ} \mathrm{C}$ in an $\mathrm{N}_{2}$ atmosphere at 1 bar. The sample was then cooled to $335^{\circ} \mathrm{C}$ and subject to vacuum again, the evacuation started when the sample was at around $355^{\circ} \mathrm{C}$. Once the second evacuation had completed the pre-treating was complete. After the pre-treatment, and before the start of the carbonation, the sample mass was $39 \%$ of the initial starting mass. After each pressure cycle ( $0-40$ bar) and at each isothermal temperature the sample was evacuated before moving on to the next isothermal temperature. This was done to remove any $\mathrm{CO}_{2}$ from the reactor that may have been decomposed from the sample. As this experiment was conducted at a constant volume there was not any gas flowing through the system when the reactor was pressurised, gas was only introduced to increase the pressure.

Figure 13 shows the results from the pTGA testing at isobaric pressure points of 0,1 , $10,20,30$ and 40 bar. The treated $\mathrm{MgCO}_{3} \cdot \mathrm{xH}_{2} \mathrm{O}$ sample increased in mass as the pressure increased. The change in mass from $0-40$ bar was around $30 \%$. As the pressure was released isothermally the $\mathrm{MgCO}_{3} \cdot \mathrm{xH}_{2} \mathrm{O}$ sample lost mass. This suggests that the $\mathrm{CO}_{2}$ was not strongly bound to the sample and the mass gain was due to surface adsorption of $\mathrm{CO}_{2}$ within the treated $\mathrm{MgCO}_{3} \cdot \mathrm{xH}_{2} \mathrm{O}$ sample and bound by Van der Walls forces.
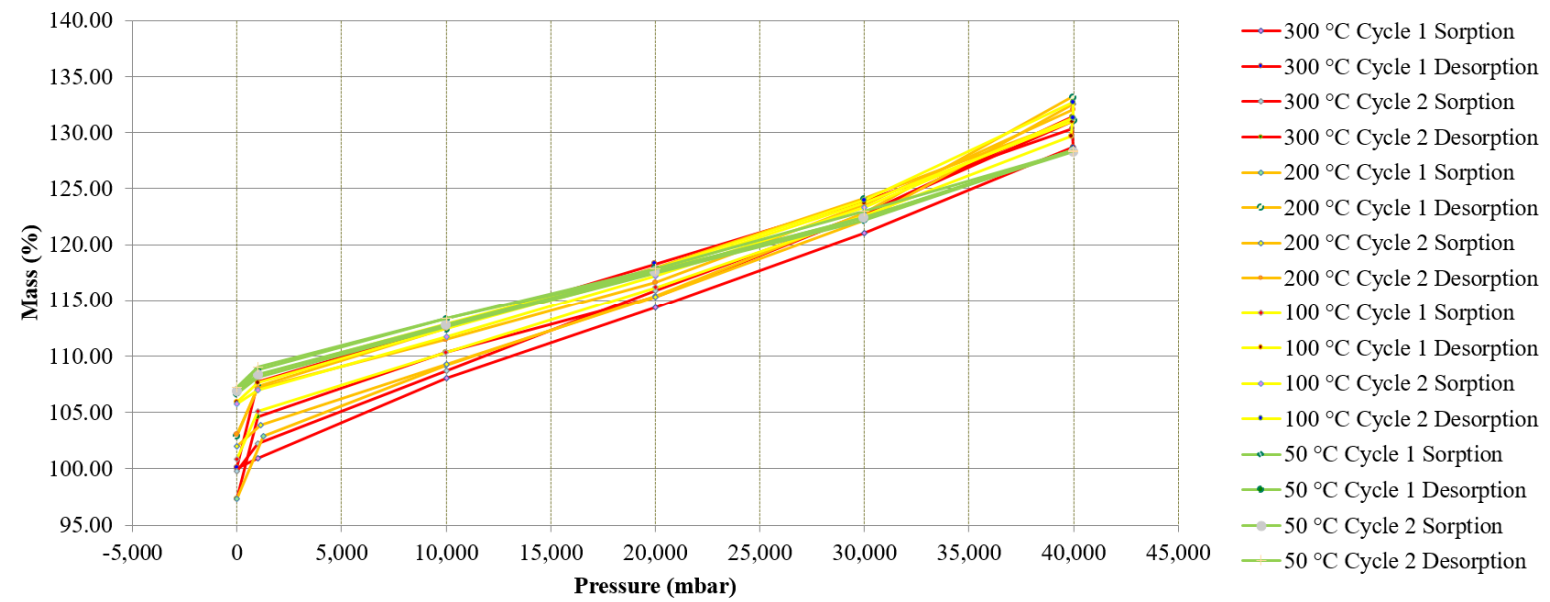

Figure 13. High-pressure TGA (pTGA) carbonation data of treated $\mathrm{MgCO}_{3} \cdot \mathrm{xH}_{2} \mathrm{O}(\mathrm{MgO})$ showing the change in mass at different isobaric pressure points and isothermal temperatures.

After completing all of the different pressure tests at the different isothermal temperatures there was a change in mass of $7 \%$ between the initial and final mass, which can be seen on Figure 13. Assuming the treated $\mathrm{MgCO}_{3} \cdot \mathrm{xH}_{2} \mathrm{O}$ sample was $\mathrm{MgO}$ the expected change in mass if $\mathrm{MgO}$ was carbonated to $\mathrm{MgCO}_{3}$ would be $109 \%$. These pTGA tests showed that this sample did not carbonate as expected and therefore did not discharge as expected. Due to this it is clearly not an ideal reaction for use as a TCES material under the range of applied conditions used in this experiment.

Research has reported a significant increase in mass when $\mathrm{MgO}$ is carbonated in a pTGA at pressures of 40 bar at different isothermal temperatures [24], this research reported experimental data using a $\mathrm{CO}_{2}$ stream that had the presence of water. The work only reported the change in mass at a fixed pressure and did not report the change in mass as the pressure was reduced following the carbonation, which is shown in Figure 13. This is important, as it gives an understanding of how the surrounding $\mathrm{CO}_{2}$ and the sample interact (treated $\mathrm{MgCO}_{3} \cdot \mathrm{xH}_{2} \mathrm{O}$ in this case) together. Figure 13 shows that the $\mathrm{CO}_{2}$ seemed to ad/desorb to the sample more as the pressure increased and decreased, through a 
physical process. Research has also suggested that $\mathrm{MgO}$ only slightly reacts with $\mathrm{CO}_{2}$ at 20 bar and $300{ }^{\circ} \mathrm{C}$ when there is not any $\mathrm{H}_{2} \mathrm{O}$ present and $\mathrm{MgO}$ is more reactive in humid $\mathrm{CO}_{2}$ [25]. Béarat et al. published a study in 2002 that showed that calcined $\mathrm{Mg}(\mathrm{OH})_{2}$ (i.e., $\mathrm{MgO}$ ) shows a small conversion (2.7 $\mathrm{wt} \%$ ) to $\mathrm{MgCO}_{3}$ when exposed to a dry $\mathrm{CO}_{2}$ gas at $375^{\circ} \mathrm{C}$ [26]. Although, the tests conducted and presented in Figure 13 were with a dry $\mathrm{CO}_{2}$ gas stream up to 40 bar and a range of temperatures, the results agreed that $\mathrm{MgO}$ in the presence of dry $\mathrm{CO}_{2}$ is not very reactive.

Song et al. published a paper in 2016 looking at the $\mathrm{CO}_{2}$ adsorption kinetics on porous $\mathrm{MgO}$ for $\mathrm{CO}_{2}$ capture use [27]. The study suggests that the adsorption kinetics of $\mathrm{CO}_{2}$ on $\mathrm{MgO}$ under different conditions has not been sufficiently investigated [27]. Information regarding the adsorption kinetics of $\mathrm{CO}_{2}$ on both treated $\mathrm{MgCO}_{3} \cdot \mathrm{xH}_{2} \mathrm{O}(\mathrm{MgO})$ and $\mathrm{Mg}(\mathrm{OH})_{2}$ can be found in Figure 13 and in Section 3.7, which present the change in mass of the aforementioned samples with changing temperature and pressure.

Figure 13 shows experimentally measured isothermal and isobaric data points. It may be possible that the carbonation of the treated $\mathrm{MgCO}_{3}(\mathrm{MgO})$ took place very slowly; however, the data collected for Figure 13 were collected over a period of more than seven days, and the sample was held isothermally and the pressure increased to greater isobars, meaning the sample was exposed to $\mathrm{CO}_{2}$ at elevated pressures for a significant amount of time. After the completion of this test there was minimal mass change (i.e., $7 \%$ total after two cycles). If carbonation took place at a very slow rate this may make the use of $\mathrm{MgCO}_{3}$ for industrial TCES difficult as a slow carbonation would result in a low power output.

\subsection{8-Hour 40 Bar pTGA Carbonation Tests of $\mathrm{MgCO}_{3} \cdot \mathrm{xH}_{2} \mathrm{O}$}

A treated $\mathrm{MgCO}_{3} \cdot \mathrm{xH}_{2} \mathrm{O}$ sample was held in a $\mathrm{CO}_{2}$ atmosphere at 40 bar pressure in the pTGA for a 48-h carbonation test. This experiment was conducted to assess if there was a slow carbonation taking place.

This test consisted of an initial decomposition of $\mathrm{MgCO}_{3} \cdot \mathrm{xH}_{2} \mathrm{O}$ to $500{ }^{\circ} \mathrm{C}$, shown in Figure 14, under a $100 \mathrm{~mL} / \mathrm{min} \mathrm{N}_{2}$ purge gas. Figure 14 shows the mass loss of the $\mathrm{MgCO}_{3} \cdot \mathrm{xH}_{2} \mathrm{O}$ as it was heated to $500{ }^{\circ} \mathrm{C}$ and the differential mass loss of the sample, with each of the three decomposition peaks annotated with temperature and remaining mass at the peaks of the differential mass loss.

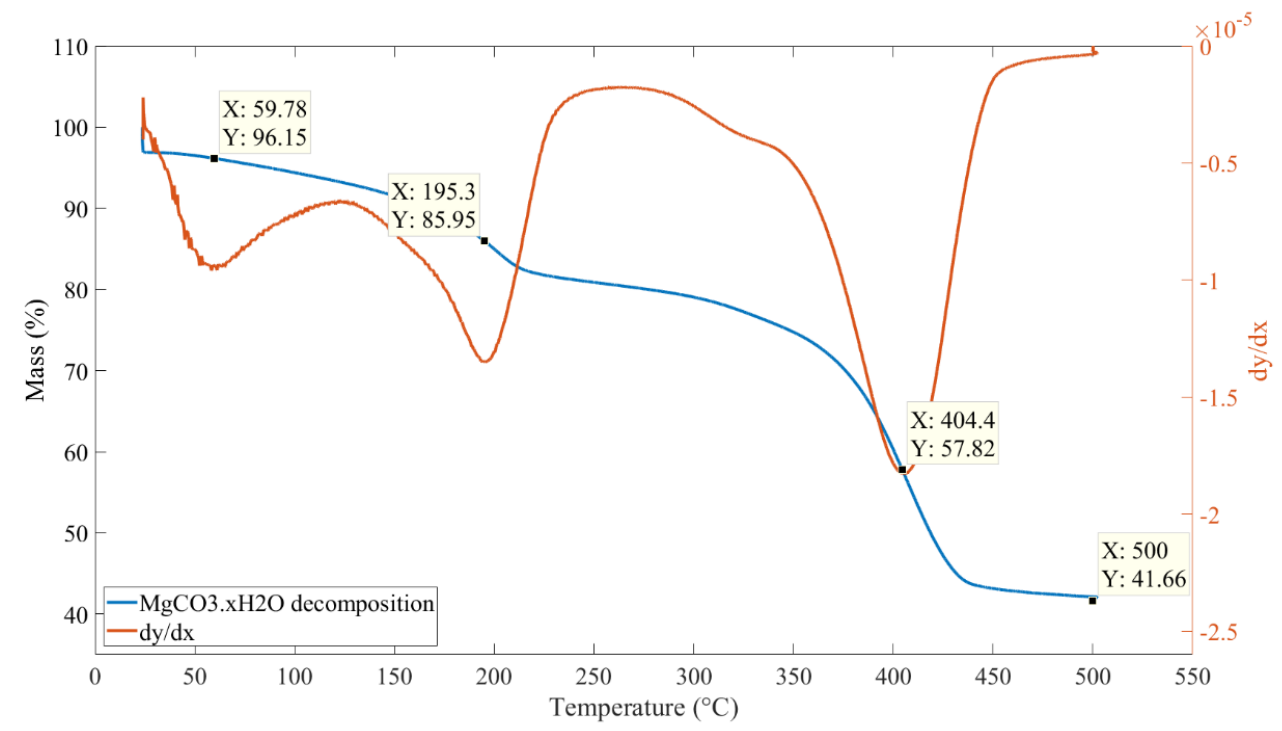

Figure 14. Decomposition of a sample of $\mathrm{MgCO}_{3} \cdot \mathrm{xH}_{2} \mathrm{O}$ to $500{ }^{\circ} \mathrm{C}$ under a $100 \mathrm{~mL} / \mathrm{min} \mathrm{N}_{2}$ purge gas within the pTGA before carbonation.

After the decomposition shown in Figure 14, the sample was cooled to $100{ }^{\circ} \mathrm{C}$ and the $\mathrm{N}_{2}$ purge gas was switched to a $\mathrm{CO}_{2}$ purge gas $(100 \mathrm{~mL} / \mathrm{min})$ and the pressure was 
increased to 40 bar (40,000 mbar). The data generated, from the 40 bar carbonation test, for percentage of initial mass (relative to a sample of $\mathrm{MgCO}_{3} \cdot \mathrm{xH}_{2} \mathrm{O}$ starting mass) with time are shown in Figure 15. Figure 15 shows that as the $\mathrm{CO}_{2}$ pressure was increased the mass also increased, which was also seen in the previous constant volume experiment shown in Figure 13. The pressure was then held at 40 bar for $48 \mathrm{~h}$. The mass of the sample increased by approximately $4 \%$ over this 48 -h period. The pressure was then reduced back to 1 bar and the $\mathrm{CO}_{2}$ flow was switched to an $\mathrm{N}_{2}$ flow of $100 \mathrm{~mL} / \mathrm{min}$. As the pressure was reduced the mass also reduced; after the 48 -h carbonation there was a difference of $6.8 \%$ in mass, which equated to a $16 \%$ increase in mass of the treated $\mathrm{MgCO}_{3} \cdot \mathrm{xH}_{2} \mathrm{O}$ sample $(\mathrm{MgO})$ from before the start of the carbonation.

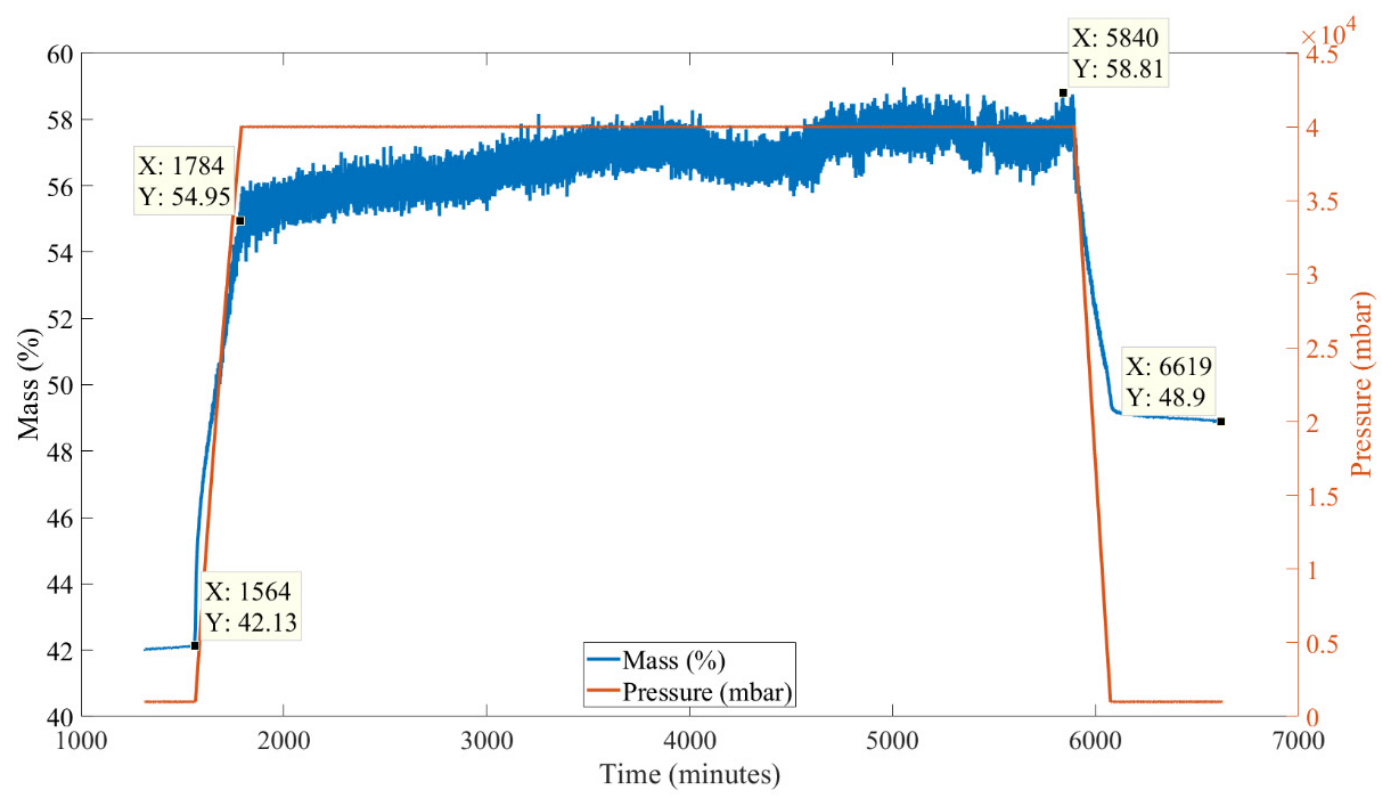

Figure 15. Long-term $(48 \mathrm{~h})$ carbonation of a treated $\mathrm{MgCO}_{3} \cdot \mathrm{xH}_{2} \mathrm{O}$ sample $(\mathrm{MgO})$ within a pTGA at $100{ }^{\circ} \mathrm{C}$ and a pressure of 40 bar with a $100 \mathrm{~mL} / \mathrm{min} \mathrm{CO}_{2}$ purge gas.

While the sample was being held at 40 bar the change in mass seen in Figure 15 was around $3.9 \%$, which equated to a $9 \%$ increase in mass of the $\mathrm{MgO}$. If the $3.9 \%$ is discounted, the change in mass of this sample seen in Figure 15 was $6.8 \%-3.9 \%=2.9 \%$, which equated to a $6.9 \%$ increase in mass of the $\mathrm{MgO}$. This was similar to the $7 \%$ change in mass found in the tests shown in Figure 13. This suggests that there was some further carbonation that took place in the sample shown in Figure 15, as it was carbonated at a higher pressure for a longer period. If the additional 3.9\% increase in mass was due to carbonation, the increase in mass of $\mathrm{MgO}$ due to this equated to $9 \%$. Nine percent of the total carbonation $\left(\mathrm{MgO}+\mathrm{CO}_{2} \Leftrightarrow \mathrm{MgCO}_{3}\right)$ enthalpy of $1054 \mathrm{~J} / \mathrm{g}$ equals $94.9 \mathrm{~J} / \mathrm{g}$ over a 48 -h period, which is an effective power output of $0.00055 \mathrm{~W} / \mathrm{g}(549 \mathrm{~W} / 1000 \mathrm{~kg})$, which is unlikely to be suitable for industrial TCES use.

Figures 14 and 15 were plotted using MATLAB, with the derivative of the mass loss curves shown in Figure 14 being smoothed to enable identification of the peaks in the derivative mass loss data using the MATLAB function "smooth".

After the 48-h carbonation of the sample shown in Figure 15 it was heated from $100{ }^{\circ} \mathrm{C}$ to $500{ }^{\circ} \mathrm{C}$ under a $100 \mathrm{~mL} / \mathrm{min}_{2}$ purge gas within the pTGA; the results of this thermal decomposition are shown in Figure 16. The sample lost $8.2 \%$ mass, which equated to a $20 \%$ mass loss of the treated $\mathrm{MgCO}_{3} \cdot \mathrm{xH}_{2} \mathrm{O}$ sample $(\mathrm{MgO})$. The remaining mass after the initial decomposition of this sample, shown in Figure 14, and after the second decomposition, shown in Figure 16, was $41.66 \%$ and $40.74 \%$, respectively. 


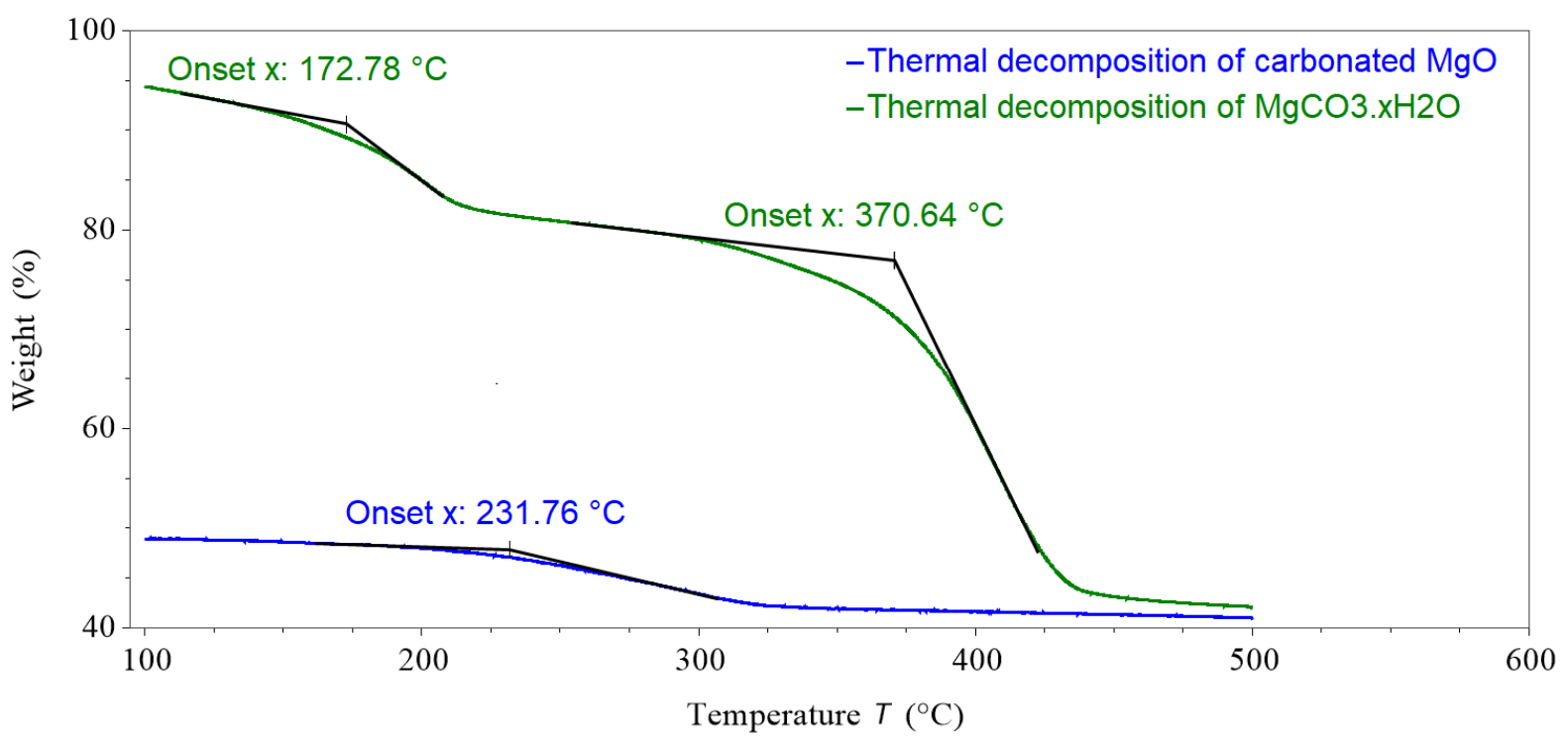

Figure 16. Thermal decomposition of a carbonated $\mathrm{MgO}$ sample (blue plot), and thermal decomposition of $\mathrm{MgCO}_{3} \cdot \mathrm{xH}_{2} \mathrm{O}$ (green plot), both within a pTGA.

The onset temperature of the thermal decomposition of the carbonated $\mathrm{MgO}$ was at $232{ }^{\circ} \mathrm{C}$. The onset temperatures for the mass loss peaks of the $\mathrm{MgCO}_{3} \cdot \mathrm{xH}_{2} \mathrm{O}$ sample were $173{ }^{\circ} \mathrm{C}$ and $371^{\circ} \mathrm{C}$. This suggests that the material created after the $\mathrm{MgO}$ was carbonated was not the same as the $\mathrm{MgCO}_{3} \cdot \mathrm{xH}_{2} \mathrm{O}$ sample.

\subsection{High-Pressure pTGA Carbonation Tests of $\mathrm{Mg}(\mathrm{OH})_{2}$}

As the $\mathrm{MgCO}_{3} \cdot \mathrm{xH}_{2} \mathrm{O}$ sample contained $\mathrm{H}_{2} \mathrm{O}$ and because it has been suggested in research that $\mathrm{MgO}$ carbonates to $\mathrm{MgCO}_{3}$ more readily in the presence of $\mathrm{H}_{2} \mathrm{O}$ [24], a further pTGA test was conducted that used $\mathrm{Mg}(\mathrm{OH})_{2}$ as the starting sample, which was heated to $250{ }^{\circ} \mathrm{C}$ in an $\mathrm{N}_{2}$ atmosphere. To prevent decomposition the $\mathrm{Mg}(\mathrm{OH})_{2}$ was only tested to $250{ }^{\circ} \mathrm{C}$ as the decomposition temperature of $\mathrm{Mg}(\mathrm{OH})_{2}$ has an onset temperature of $329^{\circ} \mathrm{C}$ and a theoretical turning temperature of $262{ }^{\circ} \mathrm{C}$.

Figure 17 shows the carbonation of $\mathrm{Mg}(\mathrm{OH})_{2}$ at different isothermal temperatures and pressures. As the pressure increased so too did the mass. For comparison at 30 bar the $\mathrm{MgCO}_{3} \cdot \mathrm{xH}_{2} \mathrm{O}$ treated sample had a mass percentage increase of $\sim 22 \%$, seen in Figure 13, whereas the $\mathrm{Mg}(\mathrm{OH})_{2}$ sample had a mass increase of only around $4-5 \%$. This result suggests that the $\mathrm{Mg}(\mathrm{OH})_{2}$ sample had less loosely bound $\mathrm{CO}_{2}$ than the treated $\mathrm{MgCO}_{3} \cdot \mathrm{xH}_{2} \mathrm{O}$ sample.

A study by Butt et al. published in 1996 investigated the kinetics of thermal dihydroxylation and carbonation of $\mathrm{Mg}(\mathrm{OH})_{2}$ [28]. This study presented results showing that $\mathrm{Mg}(\mathrm{OH})_{2}$ has a varying carbonate fraction from (6.7-16.7\%) after exposure to $\mathrm{CO}_{2}$ for $12 \mathrm{~h}$ when tested below the dissociation temperature of $\mathrm{MgCO}_{3}$ (reported in the study as $385^{\circ} \mathrm{C}$ ) [28]. The peak conversion from $\mathrm{Mg}(\mathrm{OH})_{2}$ to $\mathrm{MgCO}_{3}$ occurred near the dissociation temperature; however, carbonate was formed $(\sim 6.7 \%)$ at around $275^{\circ} \mathrm{C}$ [28]. The results presented in Figure 17 show minimal to no signs of conversion of $\mathrm{Mg}(\mathrm{OH})_{2}$ to $\mathrm{MgCO}_{3}$ at any of the range of temperatures or pressures tested. This could possibly be attributed to the testing conditions used. The carbonation reaction rate of $\mathrm{Mg}(\mathrm{OH})_{2}$ seen under the tested conditions is unlikely to be suitable for TCES as the power output is likely to be too low. 


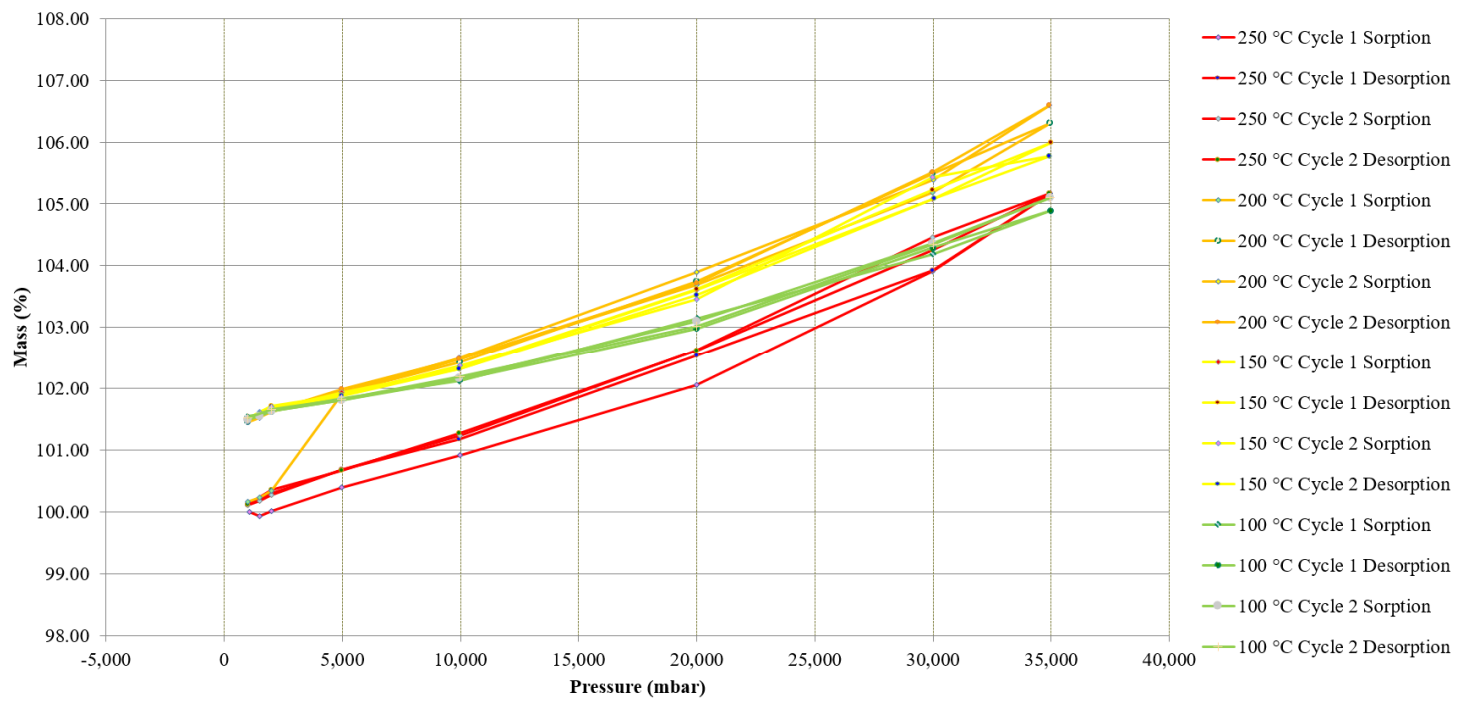

Figure 17. Isothermal and isobaric carbonation data of treated $\mathrm{Mg}(\mathrm{OH})_{2}$ within a pTGA.

In 2002 Béarat et al. published research investigating $\mathrm{Mg}(\mathrm{OH})_{2}$ dehydroxylation and carbonation for the use of $\mathrm{CO}_{2}$ sequestration [26]. Experiments were carried out with $\mathrm{Mg}(\mathrm{OH})_{2}$ at $585^{\circ} \mathrm{C}$ with changing $\mathrm{CO}_{2}$ pressure [26]. It was found that the critical pressure for $\mathrm{MgCO}_{3}$ to be formed was at $\sim 53.7 \mathrm{~atm}$ (54.4 bar) [26]. Above or below this pressure at $585^{\circ} \mathrm{C}$ the conversion from $\mathrm{Mg}(\mathrm{OH})_{2}$ to $\mathrm{MgCO}_{3}$ was reduced [26]. The study also showed that at $25.2 \mathrm{~atm}$ (25.5 bar) the critical temperature for conversion of $\mathrm{Mg}(\mathrm{OH})_{2}$ to $\mathrm{MgCO}_{3}$ is $\sim 537^{\circ} \mathrm{C}$, this is the temperature at which the highest conversion of $\mathrm{Mg}(\mathrm{OH})_{2}$ to $\mathrm{MgCO}_{3}$ was observed under these conditions. As the temperature increased or decreased from $\sim 537^{\circ} \mathrm{C}$ the conversion from $\mathrm{Mg}(\mathrm{OH})_{2}$ to $\mathrm{MgCO}_{3}$ decreased [26]. This suggests that as the $\mathrm{CO}_{2}$ pressure increases ( 25.5 bar to $54.4 \mathrm{bar}$ ) the critical temperature for peak conversion of $\mathrm{Mg}(\mathrm{OH})_{2}$ to $\mathrm{MgCO}_{3}$ increases $\left(\sim 537^{\circ} \mathrm{C}\right.$ to $\left.585^{\circ} \mathrm{C}\right)$.

A paper published by Fricker and Park in 2012 investigated the effect $\mathrm{H}_{2} \mathrm{O}$ has on the carbonation of $\mathrm{Mg}(\mathrm{OH})_{2}$ for carbon capture and storage (CCS) [29]. Fricker and Park found that $\mathrm{Mg}(\mathrm{OH})_{2}$ showed negligible carbonation at a temperature of $473 \mathrm{~K}\left(\sim 200^{\circ} \mathrm{C}\right)$ with a $\mathrm{CO}_{2}$ partial pressure of $1.03 \mathrm{MPa}(10.3 \mathrm{bar})$ and at a temperature of $573 \mathrm{~K}\left(\sim 300^{\circ} \mathrm{C}\right)$ with a $\mathrm{CO}_{2}$ partial pressure of $1.24 \mathrm{MPa}$ (12.4 bar) in dry experiments (i.e., without the presence of steam) [29]. The reasoning given for the lack of carbonation was that for a given setpoint temperature the $\mathrm{CO}_{2}$ pressure must be high enough for carbonation to occur [29]. Another dry experiment at $673 \mathrm{~K}\left(\sim 400{ }^{\circ} \mathrm{C}\right)$ with a $\mathrm{CO}_{2}$ partial pressure of $1.45 \mathrm{MPa}(14.5$ bar $)$ showed a conversion of approximately $17.6 \%$ to an anhydrous carbonate [29]. In the dry experiments conducted by Fricker and Park the $\mathrm{CO}_{2}$ pressure utilised was a maximum of 1.45 MPa (14.5 bar) [29]. Fricker and Park [29] suggested that in order for carbonation of $\mathrm{Mg}(\mathrm{OH})_{2}$ to take place without the presence of water, the $\mathrm{CO}_{2}$ pressure needs to be above a threshold for a given temperature. Therefore, if correct, it is possible that the $\mathrm{Mg}(\mathrm{OH})_{2}$ could have been converted when tested at $250^{\circ} \mathrm{C}$ and 35 bar of pressure in a $\mathrm{CO}_{2}$ environment, which was one of the tested conditions shown in Figure 17. The results shown in Figure 17 did not show any significant signs of carbonation.

\section{Conclusions}

This work investigated the potential of $\mathrm{MgCO}_{3}$ for use as a medium temperature TCES material. A variety of thermal analysis equipment was used to characterise $\mathrm{MgCO}_{3} \cdot \mathrm{xH}_{2} \mathrm{O}$. Within an $\mathrm{N}_{2}$ environment $\mathrm{MgCO}_{3}$ was shown to have a decomposition enthalpy of $1030 \mathrm{~J} / \mathrm{g}$ or $1054 \mathrm{~J} / \mathrm{g}$ determined using two different methodologies.

When decomposed within a $\mathrm{CO}_{2}$ environment the decomposition thermodynamics of $\mathrm{MgCO}_{3} \cdot \mathrm{xH}_{2} \mathrm{O}$ changed with the decomposition endset temperature increasing by $145^{\circ} \mathrm{C}$ to $612{ }^{\circ} \mathrm{C}$, compared to the decomposition in an $\mathrm{N}_{2}$ environment. This change in endset 
temperature makes the potential application for $\mathrm{MgCO}_{3}$ different from that when charged within an $\mathrm{N}_{2}$ environment. The decomposition enthalpy of $\mathrm{MgCO}_{3}$ within a $\mathrm{CO}_{2}$ environment was calculated as $1291 \mathrm{~J} / \mathrm{g}$ or $1375 \mathrm{~J} / \mathrm{g}$ determined using two different methodologies, which equated to $93 \%$ and $99 \%$ of the theoretical value, respectively.

The charging input power of $\mathrm{MgCO}_{3} \cdot \mathrm{xH}_{2} \mathrm{O}$ was shown to change from 4-8136 W/ $\mathrm{kg}$ when charged at isothermal temperatures between $250{ }^{\circ} \mathrm{C}$ and $550{ }^{\circ} \mathrm{C}$.

After high-pressure carbonation tests within a pTGA, a treated $\mathrm{MgCO}_{3} \cdot \mathrm{xH}_{2} \mathrm{O}(\mathrm{MgO})$ sample showed minimal sign of carbonation. The power output of $\mathrm{MgO}$ carbonation at 40 bar was calculated as $549 \mathrm{~W} / 1000 \mathrm{~kg}$, suggesting that $\mathrm{MgCO}_{3}$ in a pure form is not suitable for medium temperature industrial TCES.

$\mathrm{Mg}(\mathrm{OH})_{2}$ was tested at several isobaric pressures and isothermal temperatures to assess carbonation, with experiments revealing that the process conditions used did not lead to the formation of $\mathrm{MgCO}_{3}$.

In conclusion, the tested $\mathrm{MgCO}_{3} \cdot \mathrm{xH}_{2} \mathrm{O}$ was shown to have a decomposition enthalpy of $1291 \mathrm{~J} / \mathrm{g}$ or $1375 \mathrm{~J} / \mathrm{g}$ in an $\mathrm{CO}_{2}$ environment, determined using two different methodologies, suggesting that $\mathrm{MgCO}_{3} \cdot \mathrm{xH}_{2} \mathrm{O}$ has the potential to store a relatively large amount of thermal energy. However, the reverse of this thermal decomposition (the carbonation) was shown to be slow, and the calculated power output in 40 bar of $\mathrm{CO}_{2}$ was $549 \mathrm{~W} / 1000 \mathrm{~kg}$, suggesting under the range of conditions tested $\mathrm{MgCO}_{3}$ is not suitable for use as a medium temperature TCES material.

Future work is required to determine the chemical reactions that take place when the $\mathrm{MgCO}_{3} \cdot \mathrm{xH}_{2} \mathrm{O}$ is decomposed (charged) at different isothermal temperatures to explain the change in reaction kinetics at $500{ }^{\circ} \mathrm{C}$. The carbonation of treated $\mathrm{MgCO}_{3} \cdot \mathrm{xH}_{2} \mathrm{O}$ (i.e., $\mathrm{MgO}$ ) should be tested using a $\mathrm{CO}_{2}$ gas steam with varying humidity. Further tests should be conducted to investigate if there are suitable processes that could convert charged $\mathrm{MgCO}_{3}$ (i.e., $\mathrm{MgO}$ ) back to $\mathrm{MgCO}_{3}$ possibly through a two-step process, with the formation of $\mathrm{Mg}(\mathrm{OH})_{2}$ first, followed by the formation of $\mathrm{MgCO}_{3}$. The process would need to take place at suitable pressures and temperatures for $\mathrm{MgCO}_{3}$ to be considered a viable medium temperature TCES material.

Author Contributions: D.M.: Conception of the work, conduction of experiments and data acquisition, analysis and interpretation of data. Drafting revisions and final version of the work for submission. Agreement to be accountable for all aspects of the work and ensuring that questions related to the accuracy or integrity of any part of the work are appropriately investigated and resolved. G.C.: Conception of the work. Revising drafts of the work. Final approval of the version to be published. Agreement to be accountable for all aspects of the work. P.E.: Conception of the work. Revising drafts of the work. Final approval of the version to be published. Agreement to be accountable for all aspects of the work. Conceptualization, D.M., G.C. and P.E.; Data curation, D.M.; Formal analysis, D.M.; Funding acquisition, G.C. and P.E.; Investigation, D.M.; Methodology, D.M.; Project administration, G.C. and P.E.; Supervision, G.C. and P.E.; Visualization, D.M.; Writingoriginal draft, D.M.; Writing — review and editing, D.M., G.C. and P.E. All authors have read and agreed to the published version of the manuscript.

Funding: This work was supported in full by the RE-STORE project funded through the SUPERGEN Energy Storage Hub (grant number: EP/L019469/1) project, which is funded by the EPSRC.

Data Availability Statement: Loughborough University's Research Repository (http://repository. lboro.ac.uk) will be the location of data deposited regarding this journal article available for download.

Conflicts of Interest: The authors have no conflicts of interest to declare.

\section{References}

1. BP. BP Statistical Review of World Energy 68th edition. 2019. Available online: https://www.bp.com/content/dam/bp/ business-sites/en/global/corporate/pdfs/energy-economics/statistical-review/bp-stats-review-2019-full-report.pdf (accessed on 26 February 2021).

2. BP. BP Statistical Review of World Energy June 2019. 2019. Available online: https://www.bp.com/en/global/corporate/energyeconomics/statistical-review-of-world-energy.html (accessed on 26 February 2021). 
3. Masson-Delmotte, V. IPCC, 2018: Global Warming of 1.5C. An IPCC Special Report on the Impacts of Global Warming of 1.5C Above Pre-Industrial Levels and Related Global Greenhouse gas emission pathways, in the context of strengthening the global response to the threat of clima. 2018. Available online: https://www.ipcc.ch/sr15/download/\#full (accessed on 26 February 2021).

4. DBE\&IS. UK Becomes First Majour Economy to Pass Net Zero Emissions Law. 2019. Available online: https:/ /www.gov.uk/ government/news/uk-becomes-first-major-economy-to-pass-net-zero-emissions-law (accessed on 26 February 2021).

5. Tsemekidi Tzeiranaki, S. Energy Consumption and Energy Efficiency trends in the EU-28, 2000-2018. EUR 30328 EN. 2020. Available online: https:/ / ec.europa.eu/jrc/en/publication/eur-scientific-and-technical-research-reports/energy-consumptionand-energy-efficiency-trends-eu-28-2000-2018 (accessed on 26 February 2021).

6. Hammond, G.; Norman, J. Heat recovery opportunities in UK industry. Appl. Energy 2014, 116, 387-397. [CrossRef]

7. Department for Business Energy and Industrial Strategy. Energy Consumption in the UK ECUK: Consumption Data Tables (Excel); 2021. Available online: https:/ / www.gov.uk/government/statistics/energy-consumption-in-the-uk (accessed on 26 February 2021).

8. Papapetrou, M.; Kosmadakis, G.; Cipollina, A.; La Commare, U.; Micale, G. Industrial waste heat: Estimation of the technically available resource in the EU per industrial sector, temperature level and country. Appl. Therm. Eng. 2018, 138, 207-216. [CrossRef]

9. N'Tsoukpoe, K.E.; Liu, H.; Le Pierrès, N.; Luo, L. A review on long-term sorption solar energy storage. Renew. Sustain. Energy Rev. 2009, 13, 2385-2396. [CrossRef]

10. Ding, Y.; Riffat, S. Thermochemical energy storage technologies for building applications: A state-of-the-art review. Int. J. Low-Carbon Technol. 2012, 8, 106-116. [CrossRef]

11. Koçak, B.; Fernandez, A.I.; Paksoy, H. Review on sensible thermal energy storage for industrial solar applications and sustainability aspects. Sol. Energy 2020, 209, 135-169. [CrossRef]

12. Yan, T.; Wang, R.; Li, T.; Wang, L.; Fred, I.T. A review of promising candidate reactions for chemical heat storage. Renew. Sustain. Energy Rev. 2015, 43, 13-31. [CrossRef]

13. Casey, S.P.; Elvins, J.; Riffat, S.; Robinson, A. Salt impregnated desiccant matrices for 'open' thermochemical energy storageSelection, synthesis and characterisation of candidate materials. Energy Build. 2014, 84, 412-425. [CrossRef]

14. Alonso, E.; Pérez-Rábago, C.; Licurgo, J.; Fuentealba, E.; Estrada, C.A. First experimental studies of solar redox reactions of copper oxides for thermochemical energy storage. Sol. Energy 2015, 115, 297-305. [CrossRef]

15. Mahon, D.; Claudio, G.; Eames, P.C. An experimental investigation to assess the potential of using MgSO 4 impregnation and Mg $2+$ ion exchange to enhance the performance of $13 \mathrm{X}$ molecular sieves for interseasonal domestic thermochemical energy storage. Energy Convers. Manag. 2017, 150, 870-877. [CrossRef]

16. Shkatulov, A.I.; Kim, S.T.; Miura, H.; Kato, Y.; Aristov, Y.I. Adapting the MgO-CO 2 working pair for thermochemical energy storage by doping with salts. Energy Convers. Manag. 2019, 185, 473-481. [CrossRef]

17. Chen, H.; Cong, T.N.; Yang, W.; Tan, C.; Li, Y.; Ding, Y. Progress in electrical energy storage system: A critical review. Prog. Nat. Sci. 2009, 19, 291-312. [CrossRef]

18. Wentworth, W.; Chen, E. Simple thermal decomposition reactions for storage of solar thermal energy. Sol. Energy 1976, 18, 205-214. [CrossRef]

19. Wyman, C.; Castle, J.; Kreith, F. A review of collector and energy storage technology for intermetidate temperture applications. Sol. Energy 1980, 24, 517-540. [CrossRef]

20. L'Vov, B.V.; Ugolkov, V.L. Kinetics of free-surface decomposition of magnesium, strontium and barium carbonates analyzed thermogravimetrically by the third-law method. Thermochim. Acta 2004, 409, 13-18. [CrossRef]

21. Chase, M.W. NIST-JANAF Thermochemcial Tables. Malcolm W. Chase, Jr. Part 1, Al-Co and Part 2, Cr-Zr, 4th ed.; American Chemical Society: American Institute of Physics for the National Institute of Standards and Technology: Woodbury, NY, USA, 1998.

22. Song, G.; Zhu, X.; Chen, R.; Liao, Q.; Ding, Y.-D.; Chen, L. An investigation of CO2 adsorption kinetics on porous magnesium oxide. Chem. Eng. J. 2016, 283, 175-183. [CrossRef]

23. Sawada, Y.; Yamaguchi, J.; Sakurai, O.; Uematsu, K.; Mizutani, N.; Kato, M. Isothermal differential scanning calorimetry on an exothermic phenomenon during thermal decomposition of hydromagnesite $4 \mathrm{MgCO} 3 \cdot \mathrm{Mg}(\mathrm{OH}) 2 \cdot 4 \mathrm{H} 2 \mathrm{O}$. Thermochim. Acta 1979, 34, 233-237. [CrossRef]

24. Khan, N.; Dollimore, D.; Alexander, K.; Wilburn, F. The origin of the exothermic peak in the thermal decomposition of basic magnesium carbonate. Thermochim. Acta 2001, 368, 321-333. [CrossRef]

25. Highfield, J.; Haghighatlari, M.; Åbacka, J.; Zevenhoven, R.; Chen, J. Low-temperature gas-solid carbonation of magnesia and magnesium hydroxide promoted by non-immersive contact with water. RSC Adv. 2016, 6, 89655-89664. [CrossRef]

26. Fagerlund, J.; Highfield, J.; Zevenhoven, R. Kinetics studies on wet and dry gas-solid carbonation of $\mathrm{MgO}$ and $\mathrm{Mg}(\mathrm{OH}) 2$ for $\mathrm{CO}_{2}$ sequestration. RSC Adv. 2012, 2, 10380-10393. [CrossRef]

27. Béarat, H.; McKelvy, M.J.; Chizmeshya, A.V.G.; Sharma, R.; Carpenter, R.W. Magnesium hydroxide dehydroxylation/carbonation reaction processes: Implications for carbon dioxide mineral sequestration. J. Am. Ceram. Soc. 2002, 85, 742-748. [CrossRef]

28. Butt, D.P.; Lackner, K.S.; Wendt, C.H.; Conzone, S.D.; Kung, H.; Lu, Y.-C.; Bremser, J.K. Kinetics of Thermal Dehydroxylation and Carbonation of Magnesium Hydroxide. J. Am. Ceram. Soc. 1996, 79, 1892-1898. [CrossRef]

29. Fricker, K.J.; Park, A.-H.A. Effect of $\mathrm{H} 2 \mathrm{O}$ on $\mathrm{Mg}(\mathrm{OH}) 2$ carbonation pathways for combined $\mathrm{CO} 2$ capture and storage. Chem. Eng. Sci. 2013, 100, 332-341. [CrossRef] 